\title{
Comprehensive Thermodynamic Model Applicable to Highly Acidic to Basic Conditions for Isosaccharinate Reactions with $\mathrm{Ca}(\mathrm{II})$ and $\mathrm{Np}(\mathrm{IV})$
}

\author{
Dhanpat Rai, ${ }^{1, *}$ Nancy J. Hess, ${ }^{1}$ Yuanxian Xia, ${ }^{1}$ Linfeng Rao, ${ }^{1}$ \\ Herman M. Cho, ${ }^{1}$ Robert C. Moore, ${ }^{3}$ and Luc R. Van Loon ${ }^{4}$
}

Received April 24, 2003; revised August 6, 2003

\begin{abstract}
Isosaccharinate (ISA ${ }^{-}$), a degradation product of cellulose codisposed in low-level nuclear wastes, is expected to be one of the dominant complexing ligands for radionuclides, especially tetravalent actinides. This paper presents a comprehensive thermodynamic model for isosaccharinate reactions with $\mathrm{Ca}(\mathrm{II})$ and $\mathrm{Np}(\mathrm{IV})$. The model is valid for a wide range of $\mathrm{pH}$ values $(\sim 2-14)$, ISA ${ }^{-}$concentrations (ranging up to $0.1 \mathrm{~m}$ ), and ionic strengths (ranging up to $6.54 \mathrm{~m}$ ), and is based on (1) NMR investigations of HISA(aq) ( $\alpha$-D-isosaccharinic acid) and ISL(aq) [dehydration product of HISA(aq)], and the solubility of $\mathrm{Ca}(\mathrm{ISA})_{2}$ (c) as a function of $\mathrm{pH}$ and concentrations of $\mathrm{Ca}$ and $\mathrm{ISA}^{-}$; (2) $\mathrm{NpO}_{2}(\mathrm{am})$ solubility in a wide range of $\mathrm{pH}$ values $(\sim 2-14)$ and total ISA concentrations of 0.0016 and $0.008 \mathrm{~m}$ and at fixed $\mathrm{pH}$ values of approximately 5 and 12 with total ISA concentrations ranging from 0.0001 to $0.1 \mathrm{~m}$; and (3) solvent extraction of Np-ISA solutions, containing fixed $\mathrm{NaClO}_{4}$ concentrations ranging from 0.103 to 6.54 $m$ and at fixed $\mathrm{p} C_{\mathrm{H}}$ values ranging from 1.5 to 1.9 , with dibenzoylmethane. Pitzer's ion-interaction approach was used to interpret the data. The different aqueous species required to explain these data included $\mathrm{HISA}(\mathrm{aq}), \mathrm{ISL}(\mathrm{aq}), \mathrm{Ca}(\mathrm{ISA})^{+}, \mathrm{Np}(\mathrm{OH})_{3}(\mathrm{ISA})(\mathrm{aq})$, $\mathrm{Np}(\mathrm{OH})_{3}(\mathrm{ISA})_{2}^{-}, \mathrm{Np}(\mathrm{OH})_{4}(\mathrm{ISA})^{-}$, and $\mathrm{Np}(\mathrm{OH})_{4}(\mathrm{ISA})_{2}^{2-}$. The values of equilibrium constants for reactions involving these species and determined from these data provided close agreements between the observed and predicted concentrations in all of the systems investigated in this study and those reported previously.
\end{abstract}

KEY WORDS: Isosaccharinate; isosaccharinic acid; thermodynamics; ion-interaction parameters, solubility; $\mathrm{NpO}_{2}(\mathrm{am})$; solvent extraction; equilibrium constants; $\alpha$-Disosaccharinic acid; $\alpha$-D-isosaccharino-1,4-lactone.

\footnotetext{
${ }^{1}$ Pacific Northwest National Laboratory, Richland, Washington 99352.

${ }^{2}$ Berkeley National Laboratory, Berkeley, California.

${ }^{3}$ Sandia National Laboratories, Albuquerque, New Maxico.

${ }^{4}$ Paul Scherrer Institute, Switzerland.
} 


\section{INTRODUCTION}

Low- and intermediate-level nuclear wastes contain significant quantities of organic materials such as cotton, wood, and paper that have high cellulose content. The degradation products of these organic materials have been reported ${ }^{(1-12)}$ to contain soluble, low-molecular weight acids that have a high affinity for tetravalent actinides, making the tetravalent actinides, which otherwise form fairly insoluble hydrous oxides, more soluble. In particular, $\alpha$-D-isosaccharinic acid [HISA(aq)] (Fig. 1), a degradation product of cellulose, has been reported as the dominant complexing agent for tetravalent actinides under highly alkaline conditions..$^{(1,2,4,5,10)}$ However, no comprehensive thermodynamic model applicable to a wide range in $\mathrm{pH}$ and isosaccharinate concentrations is currently available for any of the tetravalent actinides. Such models and data are needed to reliably predict tetravalent actinide behavior in low- and intermediate-level nuclear waste repositories. It is known that isosaccharinate under acidic conditions transforms into HISA(aq) and ISL(aq) [ $\alpha$-D-isosaccharino-1,4-lactone; a dehydration product of HISA(aq), Fig. 1). ${ }^{(13)}$ However, reliable values are not known for the acid dissociation constant of HISA(aq) or the hydrolysis constant of ISL(aq). Therefore, fundamental data on the following aspects are necessary to determine the complexation effects of ISA ${ }^{-}$in a wide range of conditions: (1) data for protonation/deprotonation constant of HISA(aq) and equilibrium constant of hydrolysis reaction of ISL(aq), and (2) complexation constants of ISA ${ }^{-}$with tetravalent actinides applicable to a wide range in $\mathrm{pH}$ and $\mathrm{ISA}^{-}$concentrations.

In an earlier study, Rai et $a l^{(14)}$ determined the protonation/deprotonation constants of HISA(aq) through the measurement of $\mathrm{Ca}(\mathrm{ISA})_{2}$ (c) solubility as a

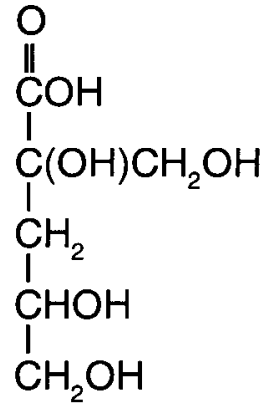

HISA(aq)

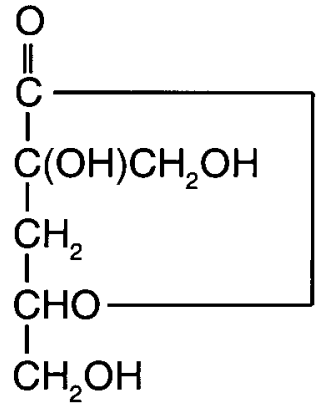

\section{ISL(aq)}

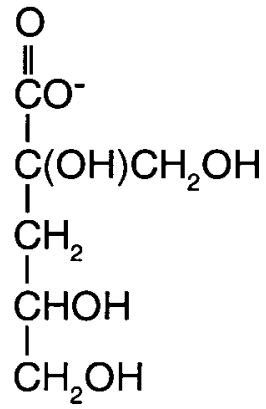

ISA $^{-}$

Fig. 1. Structures of organic ligands discussed in the paper: HISA(aq) ( $\alpha$-D-isosaccharinic acid), ISL(aq) [ $\alpha$-D-isosaccharino-1,4-lactone, a product of dehydration of HISA(aq)], and ISA $^{-}(\alpha$-D-isosaccharinate $)$. 
function of $\mathrm{pH}$. From this study they also determined the solubility product of $\mathrm{Ca}(\mathrm{ISA})_{2}$ (c) and Ca-ISA complexes. These values were then used ${ }^{(15)}$ to interpret $\mathrm{NpO}_{2}(\mathrm{am})$ solubility data in the presence of $\mathrm{Ca}$ isosaccharinate solutions in a relatively acidic and neutral region $(\mathrm{pH}<6.5)$. Since these publications, ${ }^{(15,14)}$ our, yet unpublished, data based on NMR studies [Cho et al. ${ }^{(16)}$ ] indicate that the deprotonation constant value for HISA(aq), estimated in Rai et al. ${ }^{(14)}$ is about 1.2 orders of magnitude too low, and ISL(aq) species, hitherto ignored, play a dominant role in the acidic conditions. Although Cho et al. ${ }^{(16)}$ were able to determine the equilibrium constant for hydrolysis reaction of ISL(aq) [ISL(aq) $+\mathrm{H}_{2} \mathrm{O} \rightleftharpoons \mathrm{ISA}^{-}+$ $\mathrm{H}^{+}$], the value they obtained contained a large uncertainty due to the fundamental difficulty of measuring ISA ${ }^{-}$at low $\mathrm{pH}$. In addition, recent data have also become available ${ }^{(17,18)}$ indicating that $\mathrm{CaISA}^{+}$is an important complexed species at $\mathrm{pH}$ values $>5$ in the Ca-ISA system. This discussion indicates that reliable values are not available for equilibrium constants applicable to the Ca-ISA system, including those for reactions involving ISA ${ }^{-}$in equilibrium with HISA(aq) or ISL(aq).

The main objectives of this study are to develop comprehensive models for the solubility of $\mathrm{NpO}_{2}$ (am) in the $\mathrm{Np}(\mathrm{IV})-\mathrm{H}^{+}-\mathrm{Na}^{+}-\mathrm{Ca}^{2+}-\mathrm{HISA}(\mathrm{aq})-\mathrm{ISA}^{-}-\mathrm{ISL}(\mathrm{aq})-$ $\mathrm{OH}^{-}-\mathrm{H}_{2} \mathrm{O}$ and for the solubility of $\mathrm{Ca}(\mathrm{ISA})_{2}$ (c) in the $\mathrm{Ca}^{2+}-\mathrm{H}^{+}-\mathrm{HISA}(\mathrm{aq})-$ ISA $^{-}-\mathrm{ISL}(\mathrm{aq})-\mathrm{OH}^{-}-\mathrm{H}_{2} \mathrm{O}$ systems. To accomplish this goal, we (1) conducted experiments on the solubility of $\mathrm{NpO}_{2}(\mathrm{am})$ as a function of time and in a range of $\mathrm{pH}$ values from 5 to 14 and at a fixed isosaccharinate concentration of $0.0016 \mathrm{M}$, and in a range of isosaccharinate concentrations varying from 0.0001 to $0.1 \mathrm{M}$ at a fixed $\mathrm{pH}$ value of 12 , (2) conducted experiments on the solubility of $\mathrm{Ca}(\mathrm{ISA})_{2}$ (c) at a fixed $\mathrm{pH}$ value of about 8.3 as a function of isosaccharinate concentrations ranging up to $0.2 \mathrm{M}$ and interpreted these data with data previously reported for $\mathrm{Ca}(\mathrm{ISA})_{2}(\mathrm{c})$ solubility ${ }^{(14)}$ to obtain/validate equilibrium constant values for reactions involving HISA(aq) and ISL(aq) and for Ca-ISA complexes and for use in interpreting Np data, and (3) used Pitzer's ion-interaction model to develop thermodynamic models based on the $\mathrm{NpO}_{2}(\mathrm{am})$ and $\mathrm{Ca}(\mathrm{ISA})_{2}$ (c) solubilities reported in this study and those reported previously for this system. ${ }^{(15,14)}$ Thus, the model we developed for the Np(IV)-ISA system is applicable to a wide range in pH values (2-14), HISA(aq) concentrations $(0.0001-0.1 \mathrm{M})$, and $\mathrm{NaClO}_{4}$ concentrations $(0.103-6.54 \mathrm{~m})$ in the acidic region.

\section{MATERIALS AND METHODS}

\subsection{Preparation of $\mathrm{NpO}_{2}(\mathrm{am})$}

The $\mathrm{Np}(\mathrm{IV})$ stock solution in $\mathrm{HCl}$ was prepared electrolytically. Over time, the Np stock that initially contained a significant amount of $\mathrm{Np}$ (III) converted to $\mathrm{Np}(\mathrm{IV})$. UV-Vis-NIR spectroscopic analyses of the stock solution prior to each use confirmed the absence of detectable amounts of all oxidation states other than $\mathrm{Np}(\mathrm{IV})$. The acidic $\mathrm{Np}(\mathrm{IV})$ stock solution was spiked into $20-\mathrm{mL}$ of degassed 
water containing $0.01 M \mathrm{Na}_{2} \mathrm{~S}_{2} \mathrm{O}_{4}$ in 50 -mL glass centrifuge tubes. $\mathrm{NpO}_{2}(\mathrm{am})$ was precipitated by titrating with $5 \mathrm{M} \mathrm{NaOH}$ to $\mathrm{pH}$ values of approximately 10 10.5. The precipitate was washed twice with 20 - to $30-\mathrm{mL}$ aliquots of degassed water containing $0.01 M \mathrm{Na}_{2} \mathrm{~S}_{2} \mathrm{O}_{4}$. The centrifuge tubes were kept tightly sealed with Nalgene caps to minimize exposure to the chamber atmosphere.

\subsection{Preparation of NaISA Stock Solution}

A stock solution of NaISA for use with the $\mathrm{Ca}(\mathrm{ISA})_{2}$ (c) and $\mathrm{NpO}_{2}$ (am) solubility studies was prepared using the following procedure: (1) dissolving $\mathrm{Ca}(\mathrm{ISA})_{2}$ (c) in $2 \mathrm{M} \mathrm{NaOH}$ by shaking the suspension for a few days, where dissolved Ca precipitates as $\mathrm{Ca}(\mathrm{OH})_{2}$ leaving NaISA in the aqueous phase, (2) centrifuging and separating the supernatant containing NaISA and a portion of unreacted $\mathrm{NaOH}$, (3) analyzing the concentration of ISA by carbon analysis, and (4) making appropriate $\mathrm{pH}$ adjustments, using $\mathrm{HCl}$, and dilutions of $\mathrm{NaISA}$ needed for experiments.

\subsection{Procedures}

Experiments were conducted in an atmosphere-controlled chamber under an

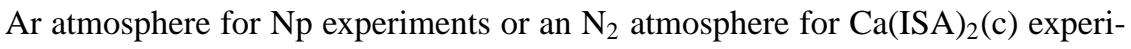
ments. Deionized distilled water, degassed by boiling and cooling in the Ar or $\mathrm{N}_{2}$ atmosphere, was used in all cases. Solubility was approached from the undersaturation direction.

\subsubsection{Solubility of Ca(ISA)2(c) in NaISA}

The $\mathrm{Ca}(\mathrm{ISA})_{2}$ (c) used in this study was prepared by the same method described by Rai et al. ${ }^{(14)}$ A $0.2 \mathrm{~g}$ of $\mathrm{Ca}(\mathrm{ISA})_{2}$ (c) was added to $50-\mathrm{mL}$ centrifuge tubes containing NaISA solutions ranging in concentrations from 0.01 to $0.2 \mathrm{M}$. The $\mathrm{pH}$ values of the suspensions were adjusted to 8.3 and the suspensions shaken continuously until analyzed. After 48 days of equilibration, the $\mathrm{pH}$ values were measured using a combination Orion-Ross glass electrode calibrated against standard $\mathrm{pH}$ buffers. The suspensions were centrifuged and aliquots of the supernatant were withdrawn for $\mathrm{C}$ analyses to quantify isosaccharinate concentrations and to filter them through CentriPrep membrane filters with 30,000 molecular weight cutoffs. The filtered solutions were analyzed for Ca using inductively coupled plasma spectroscopy. Data are listed in Appendix Table A.I.

\subsubsection{Solubility of $\mathrm{NpO}_{2}(\mathrm{am})$ in NaISA}

Because $\mathrm{Np}(\mathrm{IV})$ can be oxidized to $\mathrm{Np}(\mathrm{V})$ by $\mathrm{O}_{2}$ and such oxidation proceeds more easily in solutions of higher $\mathrm{pH}$, special precautions need to be taken to maintain the $\mathrm{Np}(\mathrm{IV})$ oxidation state. Several measures developed in previous 
studies ${ }^{(15,19)}$ were taken to minimize oxidation during the preparation of stock solutions and throughout the solubility experiments. These measures included (1) preparing the concentrated $\mathrm{Np}(\mathrm{IV})$ stock solutions $(\sim 250 \mathrm{~g} \mathrm{~Np} / \mathrm{L})$ in approximately $3.5 \mathrm{M} \mathrm{HCl}$ [where $\mathrm{Np}(\mathrm{IV})$ is relatively stable] and storing the solutions under argon, (2) conducting the experiments in the presence of a reducing agent (0.01 M Na $\mathrm{Na}_{2} \mathrm{~S}_{2} \mathrm{O}_{4}$ ), and (3) sealing the sample tubes during equilibration and sealing the ion-specific electrodes into the sample containers during measurements to avoid $\mathrm{O}_{2}$ diffusion.

Two sets of experiments were conducted to determine $\mathrm{NpO}_{2}(\mathrm{am})$ solubility in the presence of isosaccharinate. For each sample in the first experimental set, 2.5-mL aliquots of $0.1 M \mathrm{Na}_{2} \mathrm{~S}_{2} \mathrm{O}_{4}$ were added to $50-\mathrm{mL}$ centrifuge tubes, followed by $5.2 \mathrm{~mL}$ of $0.4 M$ NaISA and $5 \mathrm{mg}$ of washed $\mathrm{NpO}_{2}(\mathrm{am})$ precipitate. Degassed water or standard $\mathrm{NaOH}$ solution was added to bring the sample volume to 25 $\mathrm{mL}$. The $\mathrm{pH}$ of the solution was adjusted using $\mathrm{NaOH}$ or $\mathrm{HCl}$ to several $\mathrm{pH}$ values ranging from 5 to 12 . Additional samples were prepared in standard $\mathrm{NaOH}$ solutions ranging in concentration from 0.01 to $1.0 \mathrm{M}$. Samples in the second set were prepared similarly, except the $\mathrm{pH}$ was fixed (about 12) and the concentration of NaISA was varied from 0.0002 to $0.1 M$. For both sets, the centrifuge tubes were tightly capped and placed on a shaker. Periodically, $\mathrm{pH}$ values of the suspensions were measured using an Orion-Ross combination glass electrode calibrated against pH buffers; the electrode was sealed in the tubes to avoid contact of suspensions with the chamber atmosphere.

The suspensions were centrifuged at 2000/g for at least 10 min after different equilibration periods $(4-6,12-14,20$, or 28 days). The supernatant was then filtered through Amicon Centriplus filters (Amicon Corp.) with a 30,000 nominal molecular-weight cutoff and approximately $0.004-\mu \mathrm{m}$ pore size. An aliquot of the filtrate was spiked into a liquid scintillation cocktail for total $\mathrm{Np}$ analysis by liquid scintillation counting.

Oxidation state analyses were performed on all samples using a solvent extraction technique involving thenoyltrifluoroacetone. ${ }^{(20)}$ Data are listed in Tables A.II and A.III. The percentage Np(IV) listed in these tables is based on the portion of total soluble Np extracted by thenoyltrifluoroacetone. Using this technique, the unextracted amount $[100-\% \mathrm{~Np}(\mathrm{IV})]$ is assumed to represent $\% \mathrm{~Np}(\mathrm{~V})$.

\subsubsection{Solvent Extraction Experiments}

Our previous publication ${ }^{(21)}$ describes the preparation of stock solutions of $\mathrm{Np}$ (IV) $(\sim 60,000 \mathrm{dpm}$ in $10 \mu \mathrm{L})$ and $\mathrm{NaClO}_{4}(0.103,0.53,1.07,2.22,3.48$, 4.91 , and $6.54 \mathrm{~m}$ ), the purification procedure for dibenzoylmethane (DBM), the quantification of $\mathrm{H}^{+}$concentrations containing $\mathrm{NaClO}_{4}$ solutions, and the general procedure for determining distribution coefficients $(D$, ratio of $\mathrm{Np}$ in the organic to the aqueous phases). Only a brief description is provided here. The negative 
logarithm of $\mathrm{H}^{+}$ion concentrations $\left(\mathrm{pC}_{\mathrm{H}^{+}}\right)$in different solutions were determined from the observed $\mathrm{pH}$ electrode readings $\left(\mathrm{pH}_{\mathrm{obs}}\right)$ using the equation $\left[\mathrm{pC}_{\mathrm{H}^{+}}=\right.$ $\left.\mathrm{pH}_{\text {obs }}+A\right]$. The values of $A$ for different $\mathrm{NaClO}_{4}$ solutions $(0.03$ for $0.103 \mathrm{~m}$, 0.14 for $0.53 \mathrm{~m}, 0.27$ for $1.07 \mathrm{~m}, 0.48$ for $2.22 \mathrm{~m}, 0.69$ for $3.48 \mathrm{~m}, 0.90$ for $4.91 \mathrm{~m}$, and 1.12 for $6.54 \mathrm{~m}$ ) were determined using a Gran type of titration procedure. ${ }^{(22)}$ Isosaccharinate stock solution was prepared from $\mathrm{Ca}(\mathrm{ISA})_{2}(\mathrm{c})$. All extractions were performed in borosilicate glass scintillation vials, which were silanized using Caceci and Choppin's ${ }^{(23)}$ procedure. A reducing agent, $\mathrm{NH}_{2} \mathrm{OH} . \mathrm{HCl}$, was used to maintain $\mathrm{Np}$ in the tetravalent oxidation state.

Five-milliliter aliquots of $\mathrm{NaClO}_{4}$ adjusted to the appropriate $\mathrm{pC}_{\mathrm{H}^{+}}$and containing $0.01 M \mathrm{NH}_{2} \mathrm{OH} \cdot \mathrm{HCl}, 10 \mu \mathrm{L}$ of $\mathrm{Np}(\mathrm{IV})$ stock solution, and a known concentration of ISA (but varying between 0.0002 to $0.0028 \mathrm{~m}$ ) were shaken with 5.0 $\mathrm{mL}$ of DBM in toluene at room temperature $\left(25 \pm 1^{0} \mathrm{C}\right)$ for $1 \mathrm{hr}$. The concentration of $\mathrm{DBM}$ was adjusted depending upon the $\mathrm{NaClO}_{4}$ molality and $\mathrm{pC}_{\mathrm{H}^{+}}$of the solution so that the distribution ratio $(D)$ fell between 0.1 and 10 . Kinetic studies confirmed that the extraction equilibrium was attained in about $10 \mathrm{~min}$. The vials were centrifuged and 1.0-mL aliquots were taken from both phases to measure the alpha activity. A Wallac 1415 liquid scintillation counter was used to count the activity in HiSafe cocktail (Wallac). The remaining aqueous phase was used for $\mathrm{pH}_{\mathrm{obs}}$ measurements. Extraction data along with normalized $\mathrm{Np}(\mathrm{IV})$ aqueous concentrations used in thermodynamic analyses are reported in Table A.IV.

\subsection{Thermodynamic Model}

The ion-interaction model of Pitzer ${ }^{(24,25)}$ was used to interpret the solubility data. This aqueous thermodynamic model emphasizes a detailed description of specific ion interactions in solution. The effects of specific ion interactions on the excess solution free energy are contained in the expressions for the activity coefficients. The activity coefficients can be expressed in a virial-type expansion as

$$
\ln \gamma_{\mathrm{i}}=\ln \gamma_{\mathrm{i}}^{\mathrm{DH}}+\sum_{\mathrm{j}} \beta_{\mathrm{ij}}(\mathrm{I}) m_{\mathrm{j}}+\sum_{\mathrm{j}} \sum_{\mathrm{k}} C_{\mathrm{ijk}} m_{\mathrm{j}} m_{\mathrm{k}}+\cdots
$$

where $m$ is the molality, $\gamma_{\mathrm{i}}^{\mathrm{DH}}$ is a modified Debye-Hückel activity coefficient that is a universal function of ionic strength, and $\beta_{\mathrm{ij}}(\mathrm{I})$ and $\mathrm{C}_{\mathrm{ijk}}$ are specific for each ion interaction and are functions of ionic strength. The third virial coefficient, $\mathrm{C}$, is understood to be independent of ionic strength. A detailed description of the exact form of Eq. (1) is contained in the nonlinear least-squares programs [NONLIN and INSIGHT] ${ }^{(26)}$ for estimating the activity coefficients and calculating chemical equilibria involving multiple solid and aqueous species. We have used these programs extensively in the past to interpret solubility data for many systems including those involving isosaccharinic acid and $\mathrm{Np}(\mathrm{IV}) .{ }^{(14,15,21,27)}$ For calculation 
and plotting purposes of $\mathrm{NpO}_{2}(\mathrm{am})$ and $\mathrm{Ca}(\mathrm{ISA})_{2}$ (c) data, it was assumed that the measured molarities equal molalities because all of the solutions are either of very low ionic strength or the calculated molalities (e.g., for $1.0 \mathrm{M} \mathrm{NaOH}$ ) are not significantly different than the molarity values. Since the solvent extraction experiments were conducted in relatively dilute to concentrated $\mathrm{NaClO}_{4}$ solutions, appropriate corrections were made to convert concentrations from molarity to molality units.

\section{RESULTS AND DISCUSSION}

\subsection{Acid Dissociation and Dehydrolysis Constants of HISA(aq) and Complexation of $\mathrm{Ca}^{2+}$ with $\mathrm{ISA}^{-}$}

Rai et al. ${ }^{(14)}$ obtained extensive data on $\mathrm{Ca}(\mathrm{ISA})_{2}$ (c) solubility as a function of $\mathrm{pH}$ and $\mathrm{Ca}$ concentrations. Because preparation techniques for NaISA were unavailable at that time, they were not able to conduct studies as a function of $\mathrm{ISA}^{-}$concentrations. These data are now presented in Fig. 2 and show a progressive decrease in Ca concentrations at a fixed $\mathrm{pH}$ value of 8.3 with an increase in NaISA concentrations, similar to data presented recently by Van Loon et al. ${ }^{(17)}$ These data on $\mathrm{Ca}(\mathrm{ISA})_{2}$ (c) as a function of NaISA concentrations are critical in defining

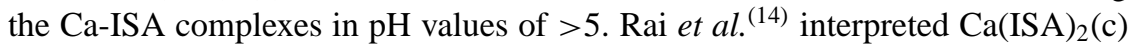
solubility as a function of $\mathrm{pH}$ using $\mathrm{HISA}(\mathrm{aq}), \mathrm{ISA}^{-}$, and $\mathrm{Ca}(\mathrm{ISA})_{2}$ (aq) species. However, this model does not explain the behavior observed in Fig. 2, predicts constant $\mathrm{Ca}$ concentration as opposed to observed decrease in Ca concentrations with the increase in NaISA concentrations, and is not consistent with NMR data, ${ }^{(16)}$ which definitively shows that both HISA(aq) and ISL(aq) are the important species under acidic conditions, and not HISA(aq) alone. The NMR data ${ }^{(16)}$ provided a reliable value for the proton dissociation constant of HISA(aq). However, the NMR data were not sufficient to provide reliable values for equilibrium constants of reactions involving ISL(aq). To develop a model that is consistent with all of these data, we reinterpreted the entire data set using the Pitzer model. For these interpretations, we relied on the $\operatorname{HISA}(\mathrm{aq})$ dissociation constant value $\left[\log K^{0}\right.$ of $-3.27 \pm 0.02$ for HISA $(\mathrm{aq}) \rightleftharpoons \mathrm{ISA}^{-}+\mathrm{H}^{+}$] based on our NMR data ${ }^{(16)}$ and fitted the values for other species. The new model (Tables I and II) is consistent with all of the data, includes HISA(aq), ISL(aq), $\mathrm{ISA}^{-}$, and $\mathrm{CaISA}^{+}$species along with a revised value for the solubility product of $\mathrm{Ca}(\mathrm{ISA})_{2}(\mathrm{c})$ and does not require $\mathrm{Ca}(\mathrm{ISA})_{2}$ (aq). A comparison of experimental data reported in Rai et al. ${ }^{(14)}$ and obtained in this study to those predicted by the new model show close agreement (Figs. 2 and 3). Our values of $1.44 \pm 0.07$ and $-6.26 \pm 0.07$, respectively, for the $\log$ of the equilibrium constant for $\left[\mathrm{Ca}^{2+}+\mathrm{ISA}^{-} \rightleftharpoons \mathrm{CaISA}^{+}\right]$and for $[\mathrm{Ca}(\mathrm{ISA}) 2(\mathrm{c})$ $\left.\rightleftharpoons \mathrm{Ca}^{2+}+2 \mathrm{ISA}^{-}\right]$are very similar to the values $(1.7$ and -6.54 , respectively) recently reported for these reactions by Van Loon et al. ${ }^{(17)}$ and the values (1.7 and $-6.36 \pm 0.10$, respectively) reported by Vercammen et al.. ${ }^{(18)} \mathrm{A}_{\text {low }} \mathrm{CaISA}^{+}$ 


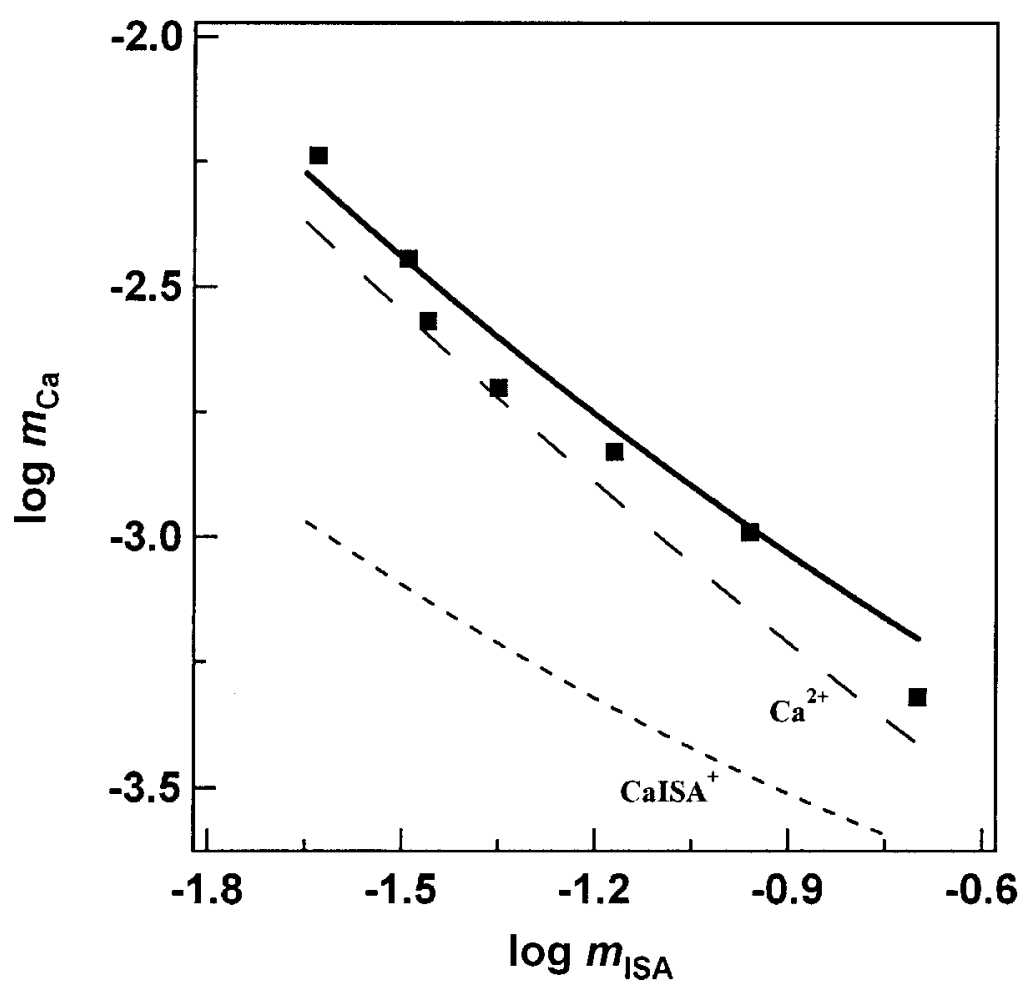

Fig. 2. Solubility of $\mathrm{Ca}(\mathrm{ISA})_{2}$ (c) as a function of NaISA concentration and at a fixed $\mathrm{pH}$ of approximately 8.3 and 48-day equilibration period. Solid line depicts predicted total concentration; other lines represent concentrations of different species, as identified, using modeling parameters reported in Tables I and II.

formation constant value shows that the isosaccharinate complexes with $\mathrm{Ca}^{2+}$ are rather weak and that this species does not contribute significantly to the total $\mathrm{Ca}$ concentrations (Figs. 2 and 3). The $\log K^{0}$ value of $0.37 \pm 0.07$ for [HISA(aq) $\rightleftharpoons$ $\operatorname{ISL}(\mathrm{aq})+\mathrm{H}_{2} \mathrm{O}$ ] determined from these data is dependent on the value selected for the proton dissociation constant of HISA(aq). However, these data show that ISL(aq), as compared with HISA(aq), are the dominant species, which is consistent with the NMR studies ${ }^{(16)}$ and lends support to the accuracy of these values for use in developing reliable models for Np(IV) systems involving ISL(aq), HISA(aq), $\mathrm{ISA}^{-}$, and $\mathrm{CaISA}^{+}$species.

\subsection{Solubility of $\mathrm{NpO}_{2}(\mathrm{am})$ in the Presence of $\mathrm{ISA}^{-}$}

Aqueous $\mathrm{Np}$ concentrations in most of the samples were relatively low (Tables A.II and A.III), so direct spectrophotometric analyses for the oxidation 
Table I. Pitzer Ion-Interaction Parameters Used in the Model ${ }^{a}$

\begin{tabular}{lllllc}
\hline \multicolumn{1}{c}{ Species } & $\beta^{(0)}$ & $\beta^{(1)}$ & $\beta^{(2)}$ & \multicolumn{1}{c}{$\mathrm{C}^{\phi}$} & Reference \\
\hline Binary Interactions & & & & & \\
$\mathrm{H}^{+}-\mathrm{Cl}^{-}$ & 0.1775 & 0.2945 & 0.00 & 0.0008 & $(32)$ \\
$\mathrm{Na}^{+}-\mathrm{Cl}^{-}$ & 0.0765 & 0.2664 & 0.00 & 0.00127 & $(32)$ \\
$\mathrm{Na}^{+}-\mathrm{OH}^{-}$ & 0.0864 & 0.253 & 0.00 & 0.0044 & $(32)$ \\
$\mathrm{Np}^{4+}-\mathrm{Cl}^{-}$ & 1.644 & 15.5 & 0.00 & 0.0995 & $(28)^{a}$ \\
$\mathrm{~Np}^{4+}-\mathrm{ClO}_{4}^{-}$ & 2.26 & 17.53 & 0.00 & 0.0995 & This study $^{b}$ \\
$\mathrm{NpOH}^{3+}-\mathrm{Cl}^{-}$ & 1.0 & 7.856 & 0.00 & 0.00 & $(28)^{a}$ \\
$\mathrm{NpOH}^{3+}-\mathrm{ClO}_{4}^{-}$ & 1.4 & 9.0 & 0.00 & 0.00 & This study $^{b}$ \\
Ternary Interactions & & & & & $(32)$ \\
$\mathrm{H}^{+}-\mathrm{Na}^{+}$ & 0.036 & & & & $(32)$ \\
$\mathrm{H}^{+}-\mathrm{Na}^{+}-\mathrm{Cl}^{-}$ & -0.004 & & & & $(32)$ \\
$\mathrm{Cl}^{-}-\mathrm{OH}^{-}$ & -0.05 & & & & $(32)$ \\
$\mathrm{Cl}^{-}-\mathrm{OH}^{-}-\mathrm{Na}{ }^{+}$ & -0.006 & & & & This study \\
$\mathrm{Np}(\mathrm{OH})_{3} \mathrm{ISA}^{b}(\mathrm{aq})-\mathrm{ClO}_{4}^{-}$ & 0.045 & & & & \\
\hline
\end{tabular}

${ }^{a}$ Assuming corresponding $\mathrm{U}(\mathrm{IV})$ parameters reported in the quoted reference apply to the $\mathrm{Np}(\mathrm{IV})$ system; our recent solvent extraction studies ${ }^{(21)}$ with $\mathrm{Np}(\mathrm{IV})$ in low to concentrated chloride solutions are consistent with these assumptions.

${ }^{b}$ These parameters are primarily important in solvent extraction data; see text for details.

${ }^{c}$ The use of this value for the reported parameter or for $\mathrm{Np}(\mathrm{OH})_{3} \mathrm{ISA}(\mathrm{aq})-\mathrm{Na}^{+}$provides identical fits. However, due to the limitations of the experimental data, it is, at present, not possible to assign this value to one of these parameters only.

state and speciation were not possible. Therefore, oxidation state distribution of aqueous $\mathrm{Np}$ was determined by solvent extraction, and the results in nearly all cases (different $\mathrm{pH}, \mathrm{ISA}^{-}$concentrations, and times) indicated that $75-90 \%$ of total aqueous $\mathrm{Np}$ was present in the tetravalent state.

The aqueous $\mathrm{Np}(\mathrm{IV})$ concentrations in equilibrium with $\mathrm{NpO}_{2}(\mathrm{am})$ are similar at different equilibration periods in each set containing (1) $0.0016 \mathrm{M} \mathrm{NaISA}$ in a range of $\mathrm{pH}$ values (Fig. 4), or (2) variable NaISA concentrations at a fixed $\mathrm{pH}$ value of about 12 (Fig. 5), indicating that steady-state conditions are reached in less than 5-6 days. Our previous studies with $\mathrm{NpO}_{2}(\mathrm{am})^{(27)}$ and other tetravalent actinide hydrous oxides ${ }^{(28,29)}$ show that equilibrium between tetravalent actinide hydrous oxides and a wide variety of electrolyte solutions with a broad range in $\mathrm{H}^{+}$concentrations is reached within a few days. The attainment of steady-state conditions in this study and the use of sampling times that exceeded the minimum required to reach equilibrium ${ }^{(27)}$ provided assurance that equilibrium is attained in our experiments.

There is a dramatic decrease in aqueous $\mathrm{Np}(\mathrm{IV})$ concentrations with increasing $\mathrm{pH}$ at $\mathrm{pH}<7$ (Fig. 4). The $\mathrm{NpO}_{2}(\mathrm{am})$ solubility in the acidic region is several orders of magnitude higher than that predicted in the absence of isosaccharinate ${ }^{(27)}$ (Fig. 4). The measured $\mathrm{Np}$ concentrations are in close agreement with the data 
Table II. Important Chemical Reactions Included in the Model

\begin{tabular}{|c|c|c|}
\hline Reaction & $\log K^{\mathrm{o}}$ & Reference \\
\hline $\mathrm{Ca}(\mathrm{ISA})_{2}(\mathrm{c}) \rightleftharpoons \mathrm{Ca}^{2+}+2 \mathrm{ISA}^{-}$ & $\begin{array}{l}-6.26 \pm 0.07 \\
-6.54 \\
-7.62 \\
-6.36 \pm 0.10\end{array}$ & $\begin{array}{c}\text { This study } \\
\text { (17) } \\
(14) \\
(18)\end{array}$ \\
\hline $\mathrm{Ca}^{2+}+\mathrm{ISA}^{-} \rightleftharpoons \mathrm{CaISA}^{+}$ & $\begin{array}{l}1.44 \pm 0.07 \\
1.70 \\
1.7\end{array}$ & $\begin{array}{c}\text { This study } \\
\text { (17) } \\
(18)\end{array}$ \\
\hline $\mathrm{Ca}^{2+}+2 \mathrm{ISA}^{-} \rightleftharpoons \mathrm{Ca}(\mathrm{ISA})_{2}(\mathrm{aq})$ & $5.4^{\mathrm{NN}}$ & $\begin{array}{c}\text { This study }{ }^{a} \\
\text { (14) }\end{array}$ \\
\hline $\mathrm{HISA}(\mathrm{aq}) \rightleftharpoons \mathrm{ISL}(\mathrm{aq})+\mathrm{H}_{2} \mathrm{O}$ & $0.37 \pm 0.07$ & This study \\
\hline $\mathrm{HISA}(\mathrm{aq}) \rightleftharpoons \mathrm{ISA}^{-}+\mathrm{H}^{+}$ & $\begin{array}{l}-3.27 \pm 0.02 \\
-4.46\end{array}$ & $\begin{array}{c}(16)^{b} \\
(14)\end{array}$ \\
\hline $\mathrm{Np}^{4+}+\mathrm{H}_{2} \mathrm{O} \rightleftharpoons \mathrm{NpOH}^{3+}+\mathrm{H}^{+}$ & -0.5 & $(33)^{c}$ \\
\hline $\mathrm{NpO}_{2}(\mathrm{am})+\mathrm{ISA}^{-}+\mathrm{H}^{+}+\mathrm{H}_{2} \mathrm{O} \rightleftharpoons \mathrm{Np}(\mathrm{OH})_{3} \mathrm{ISA}(\mathrm{aq})$ & $\begin{array}{l}2.57 \pm 0.37 \\
2.76\end{array}$ & $\begin{array}{c}\text { This study } \\
\text { (15) }\end{array}$ \\
\hline $\mathrm{NpO}_{2}(\mathrm{am})+2 \mathrm{ISA}^{-}+\mathrm{H}^{+}+\mathrm{H}_{2} \mathrm{O} \rightleftharpoons \mathrm{Np}(\mathrm{OH})_{3}(\mathrm{ISA})_{2}^{-}$ & $4.68 \pm 0.37$ & This study \\
\hline $\mathrm{NpO}_{2}(\mathrm{am})+\mathrm{ISA}^{-}+2 \mathrm{H}_{2} \mathrm{O} \rightleftharpoons \mathrm{Np}(\mathrm{OH})_{4} \mathrm{ISA}^{-}$ & $-4.76 \pm 0.37$ & This study \\
\hline $\mathrm{NpO}_{2}(\mathrm{am})+2 \mathrm{ISA}^{-}+2 \mathrm{H}_{2} \mathrm{O} \rightleftharpoons \mathrm{Np}(\mathrm{OH})_{4}(\mathrm{ISA})_{2}^{2-}$ & $-2.90 \pm 0.37$ & This study \\
\hline
\end{tabular}

${ }^{a} \mathrm{NN}=$ not needed.

${ }^{b}$ Based on NMR data ${ }^{(16)}$ and consistent with the data presented in this study.

${ }^{c}$ The equilibrium constant value is assumed to be identical to that for corresponding $\mathrm{U}$ reaction and as reported in Rai et al. ${ }^{(34)}$ This reaction does not contribute significantly to Np(IV) concentrations at any of the experimental conditions in the $\mathrm{NpO}_{2}(\mathrm{am})$ solubility study, but becomes important in solvent extraction study.

obtained by Rai et al. ${ }^{(15)}$ under identical conditions in the presence of isosaccharinate and where the experimental $\mathrm{pH}$ values overlap in both studies. The significant result obtained in this study is that the measured $\mathrm{Np}$ solubility remains low and constant under alkaline conditions exhibiting no $\mathrm{pH}$ dependence at $\mathrm{pH}$ values $\gtrsim 7$. A continued decrease in $\mathrm{Np}$ concentration with increasing $\mathrm{pH}$ is not observed under alkaline conditions, as predicted by the solubility model developed from low $\mathrm{pH}$ data only. ${ }^{(15)}$ The low Np solubility and lack of a $\mathrm{pH}$ dependence under alkaline conditions may truly be due to $\mathrm{Np}$ (IV)-ISA complexes or to detection limit problems and/or the presence of colloids. However, as is demonstrated by the results of the variable ISA ${ }^{-}$experiments (Fig. 5), the actual detection limit is approximately an order of magnitude lower than the measured concentrations; only ionic $\mathrm{Np}$ (IV) is quantified in solvent extraction tests used in this study. Therefore, the lack of $\mathrm{pH}$ dependence under highly alkaline conditions is not an experimental artifact, but is due to the presence of different Np-ISA species under alkaline conditions.

The $\mathrm{Np}(\mathrm{IV})$ concentration in equilibrium with $\mathrm{NpO}_{2}$ (am) increases approximately one order of magnitude with an order of magnitude increase in NaISA 


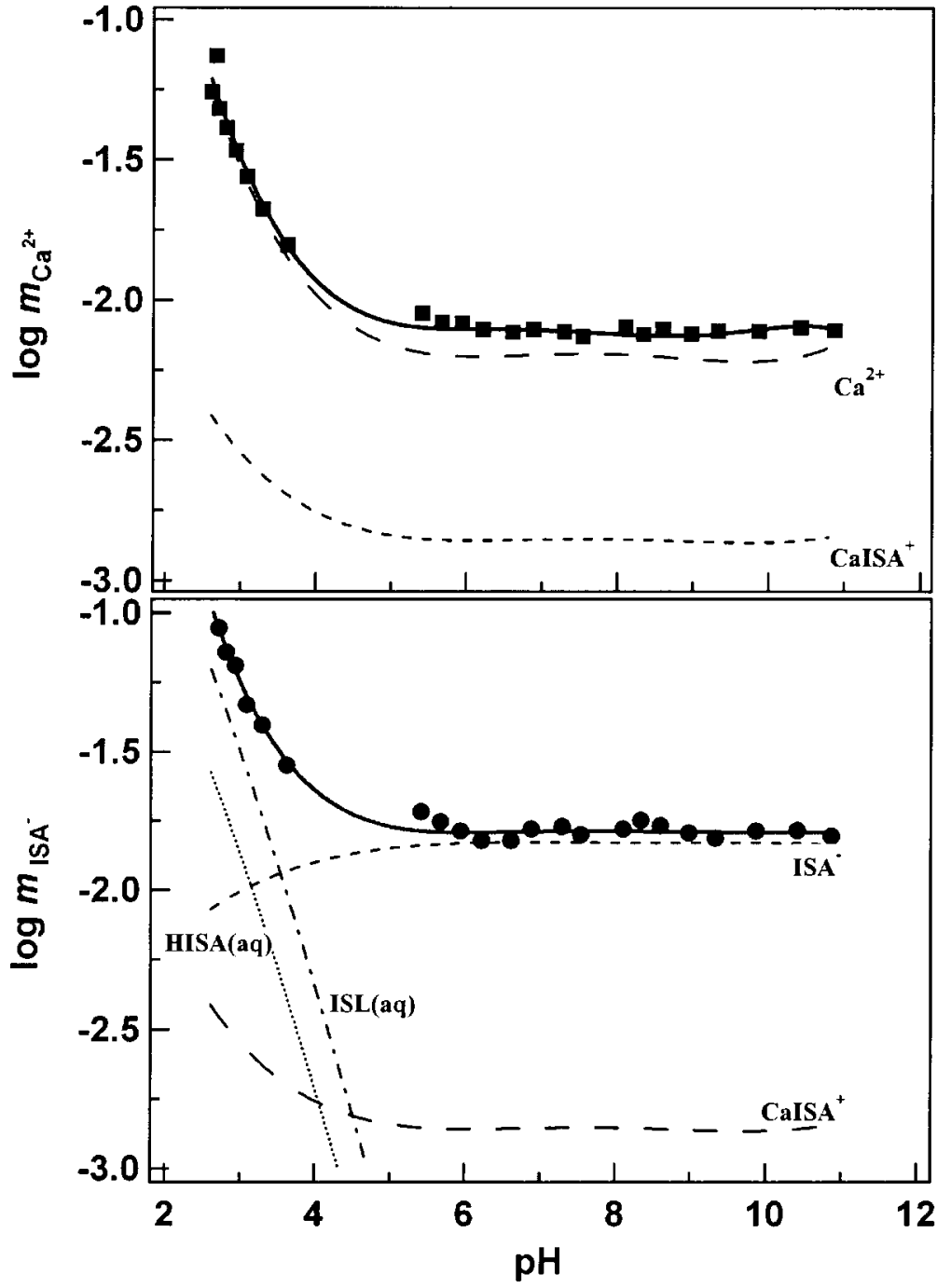

Fig. 3. Solubility of $\mathrm{Ca}(\mathrm{ISA})_{2}$ (c) as a function of $\mathrm{pH}$ and 75 -day equilibration period [experimental data of Rai et al. ${ }^{(14)}$ ]. Solid lines depict predicted total concentrations; other lines represent concentrations of different species, as identified, using modeling parameters reported in Tables I and II.

concentration at a fixed $\mathrm{pH}$ of 12 (Fig. 5). These $\mathrm{Np}$ (IV) concentrations are also similar to those observed in equilibrium with $0.0016 M$ ISA as a function of $\mathrm{pH}$ (an average of 18 data points at $\mathrm{pH}$ values $>8.5$ from Fig. 4 , plotted as a solid circle in Fig. 5), thereby providing additional assurance about the consistency 


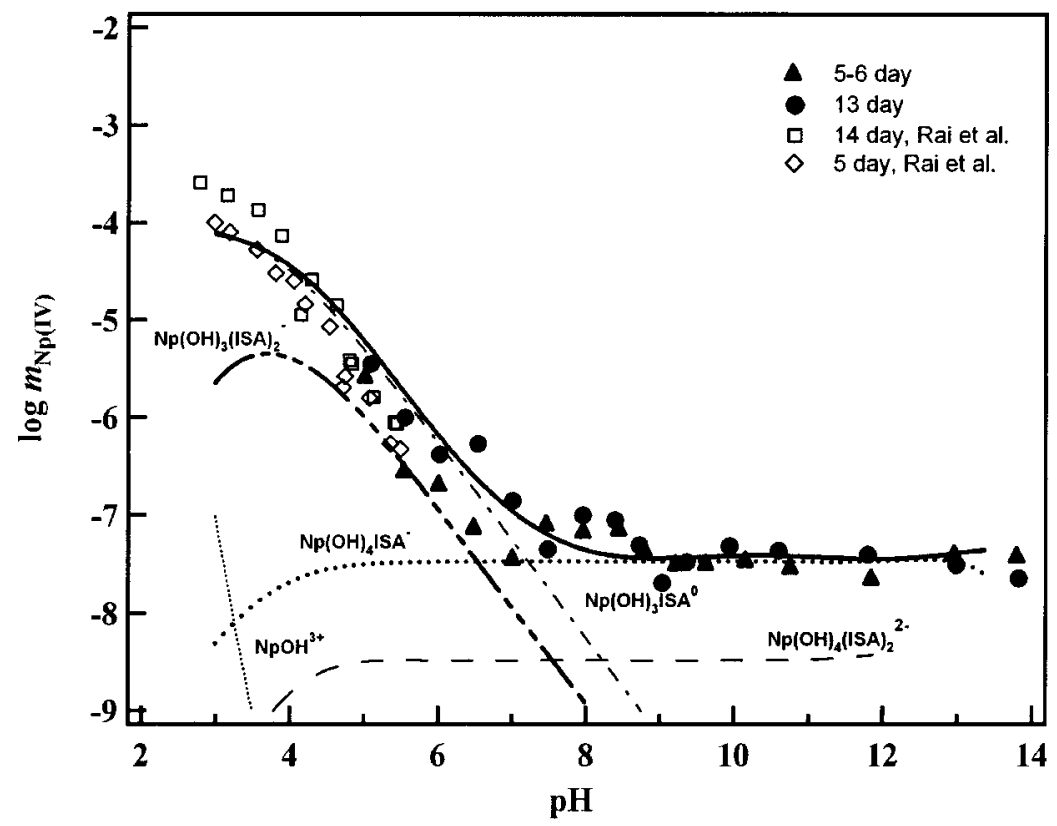

Fig. 4. Aqueous $\mathrm{Np}(\mathrm{IV})$ concentrations in equilibrium with $\mathrm{NpO}_{2}(\mathrm{am})$ as a function of $\mathrm{pH}$ and at a fixed total ISA concentration of $0.0016 \mathrm{~m}$. Relatively low $\mathrm{pH}$ data from Rai et al. ${ }^{(15)}$ The $\mathrm{pH}$ values $>12$ reported in this figure are calculated from INSIGHT based on input molarities of $\mathrm{NaOH}$ and other ions present in the system. Solid line represents total concentration, while other lines represent concentrations of different species, as identified, predicted using modeling parameters reported in Tables I and II. The line " $\left.\mathrm{Np}(\mathrm{OH})^{3+}\right)$ " represents predicted $\mathrm{Np}$ concentrations in the absence of ISA.

and the reliability of the data as a function of NaISA concentrations. Increases in $\mathrm{Np}(\mathrm{IV})$ concentrations with increases in ISA ${ }^{-}$concentration were also observed for $\mathrm{NpO}_{2}(\mathrm{am})$ suspensions equilibrated at $\mathrm{pH} 5$ (Fig. 6). However, the measured $\mathrm{Np}$ concentrations are nearly three orders of magnitude higher at $\mathrm{pH} 5$ (Fig. 6) than at $\mathrm{pH} 12$ (Fig. 5). Although increases in $\mathrm{NpO}_{2}(\mathrm{am})$ solubility are observed in both acidic and alkaline conditions, the dominant species must certainly be different in these two regimes. Reasons for these differences are (1) the solubility of $\mathrm{NpO}_{2}(\mathrm{am})$ decreases with the increase in $\mathrm{pH}$ at values between 2 and 7 (Figs. 4), which would require species, such as $\mathrm{Np}(\mathrm{OH})_{\mathrm{x}}(\mathrm{ISA})_{\mathrm{y}}^{4-(\mathrm{x}+\mathrm{y})}$, where $x$ would have a value of less than 4 and $y$ a value $\geq 1$, and (2) the solubility of $\mathrm{NpO}_{2}(\mathrm{am})$ is nearly constant at $\mathrm{pH}$ values between about 8 and 14 (Fig. 4), which would require species such as $\mathrm{Np}(\mathrm{OH})_{4}(\mathrm{ISA})_{\mathrm{y}}^{-\mathrm{y}}$ with $y \geq 1$. Consistent with this observation, Rai et al. ${ }^{(15)}$ proposed $\mathrm{Np}(\mathrm{OH})_{3} \mathrm{ISA}^{0}$ and $\mathrm{Np}(\mathrm{OH})_{2}(\mathrm{ISA})_{2}^{-}$species to explain the observed $\mathrm{NpO}_{2}(\mathrm{am})$ solubility behavior in the acidic region. Thermodynamic interpretations of the data currently available are discussed in the next section. 


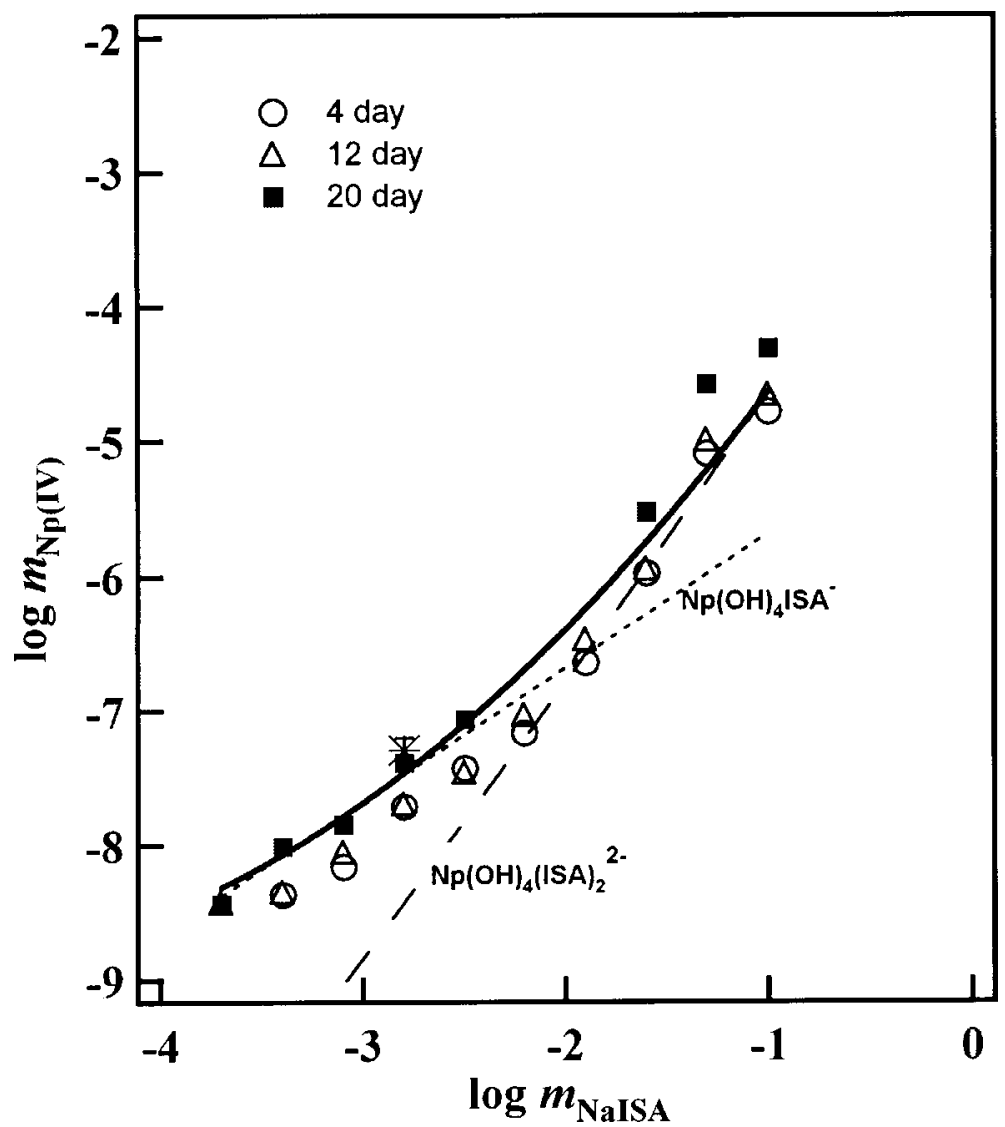

Fig. 5. Aqueous $\mathrm{Np}(\mathrm{IV})$ concentrations in equilibrium with $\mathrm{NpO}_{2}(\mathrm{am})$ as a function of time and NaISA concentrations at a fixed $\mathrm{pH}$ of $\sim 12$. The solid circle with horizontal lines represents the mean and standard deviation of $\mathrm{Np}(\mathrm{IV})$ concentration $\left(\log m_{\mathrm{Np}(\mathrm{IV})}=\right.$ $-7.292 \pm 0.09$ ) of 16 samples with $\mathrm{pH}$ values $>8.5$, which are plotted in Fig. 4. Solid line represents total concentrations, while other lines represent concentrations of different species, as identified, predicted using modeling parameters reported in Tables I and II.

\subsection{Thermodynamic Analyses of $\mathrm{NpO}_{2}(\mathrm{am})$ Solubility Data}

Because of the revised value of the dissociation constant of HISA(aq) and the new values involving CaISA ${ }^{+}$and ISL(aq) determined in this study (Table II), and because of the need to develop a comprehensive model for the Np(IV)-ISA system, the experimental data and those presented by Rai et $_{\text {al. }}{ }^{(15)}$ were interpreted together to develop a reliable model that would be consistent with all of the available data. The aqueous $\mathrm{Np}(\mathrm{OH})_{3} \mathrm{ISA}(\mathrm{aq}), \mathrm{Np}(\mathrm{OH})_{3}(\mathrm{ISA})_{2}^{-}, \mathrm{Np}(\mathrm{OH})_{4}(\mathrm{ISA})^{-}$, and $\mathrm{Np}(\mathrm{OH})_{4}(\mathrm{ISA})_{2}^{2-}$ make up the combination of complex species that provided close 


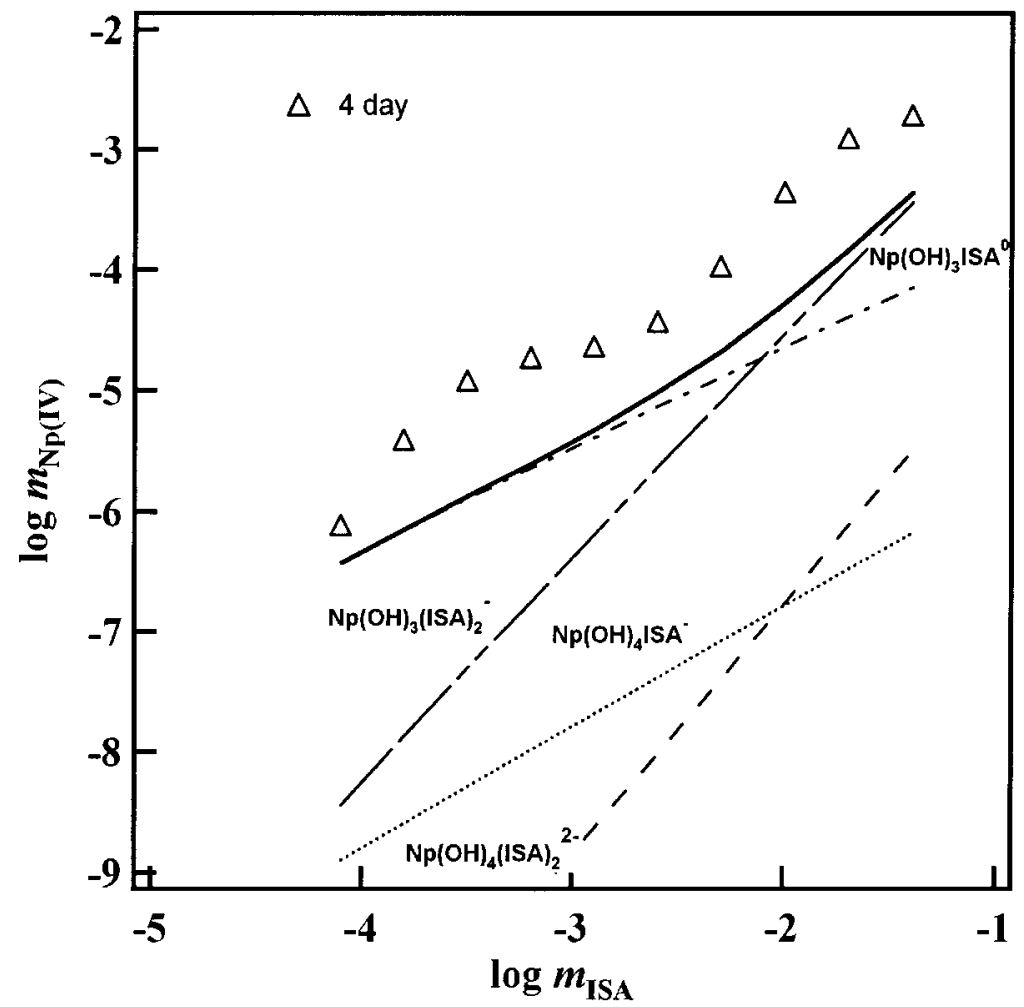

Fig. 6. Aqueous $\mathrm{Np}(\mathrm{IV})$ concentrations in equilibrium with $\mathrm{NpO}_{2}(\mathrm{am})$ as a function of $\mathrm{NaISA}$ concentrations ${ }^{(15)}$ at a fixed $\mathrm{pH}$ value of $\sim 5$. Solid line represents total concentrations, while other lines represent concentrations of different species, as identified, predicted using modeling parameters reported in Tables I and II.

agreement with the observed $\mathrm{NpO}_{2}(\mathrm{am})$ solubilities in a range of $\mathrm{pH}$ values varying from 2 to 14 and at fixed NaISA concentrations of 0.0016 or $0.008 M$ (Figs. 4 and 7) and $\mathrm{NaISA}$ concentrations ranging from 0.0001 to $0.1 \mathrm{M}$ and at fixed $\mathrm{pH}$ values of 5 or 12 (Figs. 5 and 6). The relative distribution of these species as a function of $\mathrm{pH}$ and NaISA concentrations are shown in Figs. 4 through 7. These data show that at a given isosaccharinate concentration, primarily two species are required to explain the observed $\mathrm{NpO}_{2}$ (am ) solubility from $\mathrm{pH}$ values of 2 all the way to approximately 14 . The species $\mathrm{Np}(\mathrm{OH})_{3} \mathrm{ISA}(\mathrm{aq})$ or $\mathrm{Np}(\mathrm{OH})_{3}(\mathrm{ISA})_{2}^{-}$are required for $\mathrm{pH}$ values of $\$ 7$ and $\mathrm{Np}(\mathrm{OH})_{4}(\mathrm{ISA})^{-}$or $\mathrm{Np}(\mathrm{OH})_{4}(\mathrm{ISA})_{2}^{2-}$ are required for $\mathrm{pH}$ values of $\gtrsim 7$. The species $\mathrm{Np}(\mathrm{OH})_{3} \mathrm{ISA}^{0}$ or $\mathrm{Np}(\mathrm{OH})_{4}(\mathrm{ISA})^{-}$are important at total ISA concentrations of $\lesssim 0.01 M$, while $\mathrm{Np}(\mathrm{OH})_{3}(\mathrm{ISA})_{2}^{-}$or $\mathrm{Np}(\mathrm{OH})_{4}(\mathrm{ISA})_{2}^{2-}$ are important at total ISA concentrations of $\gtrsim 0.01 M$. The $\mathrm{NpO}_{2}(\mathrm{am})$ solubility 


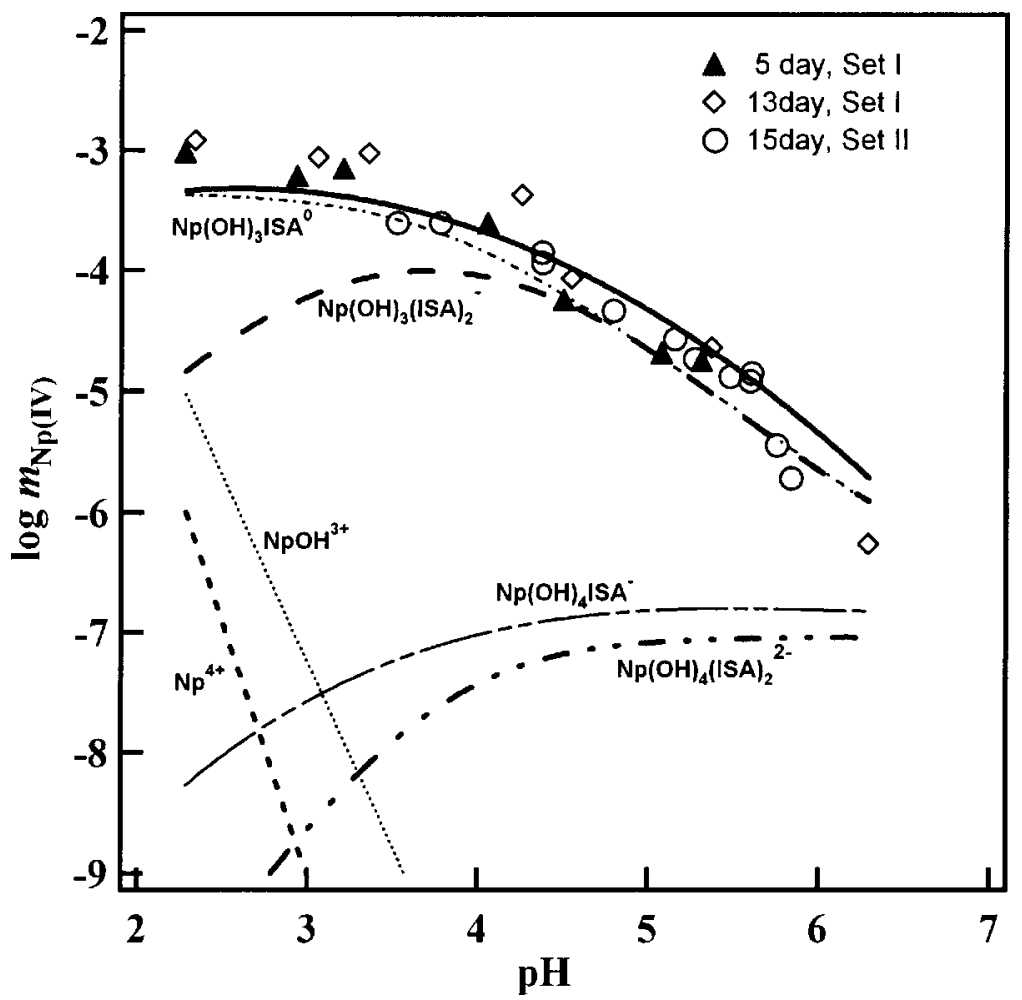

Fig. 7. Aqueous $\mathrm{Np}(\mathrm{IV})$ concentrations ${ }^{(15)}$ in equilibrium with $\mathrm{NpO}_{2}(\mathrm{am})$ as a function of time and $\mathrm{pH}$ at a fixed total ISA concentration of $0.008 \mathrm{~m}$. Solid line represents total concentrations, while other lines represent concentrations of different species, as identified, predicted using modeling parameters reported in Tables I and II.

reactions involving these species are reported in Eqs. (2-5)

$$
\begin{aligned}
\mathrm{NpO}_{2}(\mathrm{am})+\mathrm{ISA}^{-}+\mathrm{H}^{+}+\mathrm{H}_{2} \mathrm{O} & \rightleftharpoons \mathrm{Np}(\mathrm{OH})_{3} \mathrm{ISA}^{0} \\
\mathrm{NpO}_{2}(\mathrm{am})+2 \mathrm{ISA}^{-}+\mathrm{H}^{+}+\mathrm{H}_{2} \mathrm{O} & \rightleftharpoons \mathrm{Np}(\mathrm{OH})_{3}(\mathrm{ISA})_{2}^{-} \\
\mathrm{NpO}_{2}(\mathrm{am})+\mathrm{ISA}^{-}+2 \mathrm{H}_{2} \mathrm{O} & \rightleftharpoons \mathrm{Np}(\mathrm{OH})_{4}(\mathrm{ISA})^{-} \\
\mathrm{NpO}_{2}(\mathrm{am})+2 \mathrm{ISA}^{-}+2 \mathrm{H}_{2} \mathrm{O} & \rightleftharpoons \mathrm{Np}(\mathrm{OH})_{4}(\mathrm{ISA})_{2}^{2-}
\end{aligned}
$$

The equilibrium constants for these reactions calculated from these data were $2.57 \pm 0.37,4.68 \pm 0.37,-4.76 \pm 0.37$, and $-2.90 \pm 0.37$, respectively. When these equilibrium reactions for the dissolution of $\mathrm{NpO}_{2}$ (am) (Eqs. 2-5) are combined with the $\mathrm{NpO}_{2}(\mathrm{am})$ solubility product $\left(\log K_{\mathrm{sp}}=-54.9\right),{ }^{(27)}$ they provide 
the logarithm of the equilibrium constant of 43.47 for $\left[\mathrm{Np}^{4+}+3 \mathrm{OH}^{-}+\mathrm{ISA}^{-} \rightleftharpoons\right.$ $\left.\mathrm{Np}(\mathrm{OH})_{3} \mathrm{ISA}^{0}\right], 45.58$ for $\left[\mathrm{Np}^{4+}+3 \mathrm{OH}^{-}+2 \mathrm{ISA}^{-} \rightleftharpoons \mathrm{Np}(\mathrm{OH})_{3}(\mathrm{ISA})_{2}^{-}\right], 50.14$ for $\left[\mathrm{Np}^{4+}+4 \mathrm{OH}^{-}+\mathrm{ISA}^{-} \rightleftharpoons \mathrm{Np}(\mathrm{OH})_{4} \mathrm{ISA}^{-}\right]$, and 52.00 for $\left[\mathrm{Np}^{4+}+4 \mathrm{OH}^{-}+\right.$ $\left.2 \mathrm{ISA}^{-} \rightleftharpoons \mathrm{Np}(\mathrm{OH})_{4}(\mathrm{ISA})_{2}^{2-}\right]$. No values of isosaccharinate complexes of $\mathrm{Np}(\mathrm{IV})$ or of other tetravalent actinides are available other than those Rai et al. ${ }^{(15)}$ determined for Np-ISA complexes, based on the limited data under acidic conditions or for those Moreton ${ }^{(5)}$ and Greenfield et al. ${ }^{(3,4)}$ proposed for Pu(IV)-ISA complexes based on a few samples at $\mathrm{pH} 12$, and Vercammen et al. ${ }^{(12)}$ proposed for $\mathrm{Th}(\mathrm{IV})$ based on studies with ion-exchange resin at $\mathrm{pH}$ 13.3. Rai et al. ${ }^{(15)}$ proposed two species $\left[\mathrm{Np}(\mathrm{OH})_{3} \mathrm{ISA}^{0}\right.$ and $\left.\mathrm{Np}(\mathrm{OH})_{2}(\mathrm{ISA})_{2}^{-}\right]$and the value for the equilibrium constant they determined for $\mathrm{Np}(\mathrm{OH})_{3} \mathrm{ISA}^{0}$ is very similar to the value determined in this study (Table II). This is not surprising since both values are based on the same experimental data. However, reanalyses of Rai et al. ${ }^{(15)}$ data using a revised thermodynamic model (Tables I and II) showed that the species $\mathrm{Np}(\mathrm{OH})_{2}(\mathrm{ISA})_{2}^{-}$ were not required to fit the data.

As we observed in this study for $\mathrm{Np}(\mathrm{IV})$, Moreton ${ }^{(5)}$ and Greenfield et al. ${ }^{(3,4)}$ also observed an increase in $\mathrm{Pu}(\mathrm{IV})$ concentration with the increase in $\mathrm{ISA}^{-}$ concentration at $\mathrm{pH} 12$. Rather than interpreting the data under highly alkaline conditions, as we did using mixed hydroxy-ISA complexes $\left[\mathrm{Np}(\mathrm{OH})_{4} \mathrm{ISA}^{-}\right.$and $\left.\mathrm{Np}(\mathrm{OH})_{4}(\mathrm{ISA})_{2}^{2-}\right]$, they interpreted their data assuming complexes with isosaccharinate-containing deprotonated hydroxyl groups. The reactions they proposed are

$$
\begin{aligned}
\mathrm{PuO}_{2}(\mathrm{am})+\mathrm{ISA}^{-} & \rightleftharpoons \mathrm{Pu}\left(\mathrm{ISAH}_{-4}\right)^{-}+2 \mathrm{H}_{2} \mathrm{O} \\
\mathrm{PuO}_{2}(\mathrm{am})+2 \mathrm{ISA}^{-} & \rightleftharpoons \mathrm{Pu}\left(\mathrm{ISAH}_{-2}\right)_{2}^{2-}+2 \mathrm{H}_{2} \mathrm{O}
\end{aligned}
$$

where ISAH ${ }_{-\mathrm{m}}$ represents the deprotonation of $m$ hydroxyl groups of isosaccharinate. ${ }^{5}$ Like Reactions 4 and 5, Reactions 6 and 7 have no explicit $\mathrm{pH}$ dependence, so $\mathrm{Pu}(\mathrm{IV})$ solubility is expected to remain constant as a function of $\mathrm{pH}$. Unfortunately, $\mathrm{Pu}(\mathrm{IV})$ solubility measurements were not made as a function of $\mathrm{pH}$ at constant isosaccharinate concentration and the predicted behavior cannot be verified. However, because the behavior of $\mathrm{Pu}(\mathrm{IV})$ and $\mathrm{Np}(\mathrm{IV})$ are expected to be similar and $\mathrm{Np}(\mathrm{IV})$ solubility does not exhibit a $\mathrm{pH}$ dependence under alkaline conditions (Fig. 4), the deprotonation reactions (Eqs. 6 and 7) of isosaccharinate hydroxyl groups can also explain our solubility data under alkaline conditions. Spectroscopic techniques, such as nuclear magnetic resonance (NMR), are required to distinguish between the mixed hydroxy-ISA complexes proposed in Eqs. 4 and 5 and the hydroxyl deprotonation reactions proposed in Eqs. 6 and 7. Our ${ }^{13} \mathrm{C}-\mathrm{NMR}$ studies with $\mathrm{Na}$ and $\mathrm{Ca}$ solutions of isosaccharinate ${ }^{(16)}$ show that

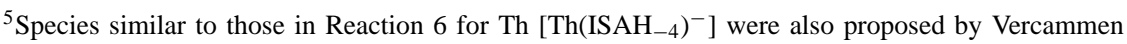
et al. $^{(12)}$ to interpret their adsorption data for an ion-exchange resin at $\mathrm{pH} 13.3$.
} 
deprotonation of the carboxylic acid is complete by about $\mathrm{pH} 5$ and that no further deprotonation reactions of isosaccharinate are apparent in the $\mathrm{pH}$ range from 5 to 12 . These preliminary data support the formation of mixed hydroxy-ISA complexes and are consistent with our modeling results, which indicated that species of the type $\mathrm{Np}(\mathrm{OH})_{4}(\mathrm{ISA})_{\mathrm{y}}^{-\mathrm{y}}$ (with $y \geq 1$ ) control the $\mathrm{Np}$ solubility from $\mathrm{pH} 8$ to 14 (Figs. 4 and 5). The complexation of isosaccharinate with tetravalent actinides may shift the deprotonation of the hydroxyl group to lower $\mathrm{pH}$ values such that studies specifically with complexed tetravalent actinides would be required to determine whether the complexation involves deprotonation of hydroxyl groups or hydrolyzed tetravalent actinides. However, regardless of how the complexes are formed, the overall net reactions are well understood and provide reliable data for predicting $\mathrm{Np}$ behavior in a wide range of $\mathrm{pH}$ values and isosaccharinate concentrations.

\subsection{Extending the Thermodynamic Model to High Acidity and Ionic Strength}

The thermodynamic model described above is based on the $\mathrm{NpO}_{2}(\mathrm{am})$ solubility data obtained in relatively dilute electrolytes. For this purpose, we conducted extensive solvent extraction studies in the $\mathrm{p} C_{\mathrm{H}^{+}}$range of 1.5 to 1.9 , total isosaccharinate concentrations varying from 0.0002 to $0.0028 \mathrm{~m}$, and $\mathrm{NaClO}_{4}$ concentrations fixed at different molalities ranging from 0.103 to $6.54 \mathrm{~m}$ (Table A.IV). Based on the model described above, the dominant Np-ISA complex species in the solvent extraction data is expected to be $\mathrm{Np}(\mathrm{OH})_{3} \mathrm{ISA}^{0}$, and $\mathrm{Np}^{4+}$ and $\mathrm{NpOH}^{3+}$ are expected to become more important than in the solubility data. Therefore, Pitzer ion-interaction parameters cannot be ignored for $\mathrm{Np}^{4+}$ and $\mathrm{NpOH}^{3+}$ in these concentrated electrolytes. Pitzer parameters are not available for these species with $\mathrm{ClO}_{4}^{-}$, the major electrolyte anion in this system. However, it has been suggested ${ }^{(21)}$ that binary parameters ${ }^{(28)}$ for $\mathrm{U}^{4+}-\mathrm{Cl}^{-}$and $\mathrm{UOH}^{3+}-\mathrm{Cl}^{-}$ can be used for the $\mathrm{ClO}_{4}^{-}$interactions with corresponding $\mathrm{Np}$ species. Defining these parameters from these solvent extraction studies alone in relatively constant $\mathrm{p} C_{\mathrm{H}^{+}}$values and as a function of a limited range in ISA ${ }^{-}$concentrations is difficult. Therefore, several different modeling runs were conducted to quantify these parameters. The parameters that provided the best fits to all of the data included $\beta^{(0)}=2.26$ and $\beta^{(1)}=17.53$ for $\mathrm{Np}^{4+}-\mathrm{ClO}_{4}^{-}$, and $\beta^{(0)}=1.4$ and $\beta^{(1)}=9.0$ for $\mathrm{NpOH}^{3+}-\mathrm{ClO}_{4}^{-}$, whereas the only other reported experimental values ${ }^{(28)}$ for the ion-interaction parameters of tetravalent actinides are $\beta^{(0)}=1.644$ and $\beta^{(1)}=15.5$ for $\mathrm{U}^{4+}-\mathrm{Cl}^{-}$, and $\beta^{(0)}=1.0$ and $\beta^{(1)}=7.856$ for $\mathrm{UOH}^{3+}-\mathrm{Cl}^{-}$, indicating that the perchlorate system requires larger values for these parameters than the chloride system. We believe that the values of these parameters with perchlorate are reasonable because (1) the reported $\beta^{(0)}$ and $\beta^{(1)}$ values ${ }^{(25)}$ for trivalent rare earths with 
$\mathrm{ClO}_{4}^{-}$are approximately 30 and $17 \%$, respectively, higher than the values for the corresponding parameters with $\mathrm{Cl}^{-}$; the values that we determined in this study with $\mathrm{ClO}_{4}^{-}$are consistent with this expectation; (2) Felmy et al. ${ }^{(30)}$ reported orders of magnitude lower $\mathrm{ThO}_{2}(\mathrm{am})$ solubility in $\mathrm{NaClO}_{4}$ solutions as compared with $\mathrm{NaCl}$, indicating that higher values for $\beta^{(0)}$ and $\beta^{(1)}$ will be required for $\mathrm{NaClO}_{4}$ solutions as compared with $\mathrm{NaCl}$, again consistent with our findings; and (3) in trying to explain the observed $\mathrm{ThO}_{2}(\mathrm{am})$ solubility as a function of $\mathrm{Na}_{2} \mathrm{CO}_{3}$ in $\mathrm{NaCl}$ solutions, Felmy et al. ${ }^{(31)}$ determined $\theta=1.8$ for $\mathrm{Th}\left(\mathrm{CO}_{3}\right)_{5}^{6-}-\mathrm{Cl}^{-}$as compared to $\theta=5.5$ for $\mathrm{Th}\left(\mathrm{CO}_{3}\right)_{5}^{6-}-\mathrm{ClO}_{4}^{-}$, indicating higher values for Pitzer parameters in perchlorate than in chloride systems. In addition to parameters for $\mathrm{Np}^{4+}-\mathrm{ClO}_{4}^{-}$ and $\mathrm{NpOH}^{3+}-\mathrm{ClO}_{4}^{-}$, the solvent extraction data also required a value of 0.045 for $\mathrm{Np}(\mathrm{OH})_{3} \mathrm{ISA}^{0}-\mathrm{ClO}_{4}^{-}$or for $\mathrm{Np}(\mathrm{OH})_{3} \mathrm{ISA}^{0}-\mathrm{Na}^{+}$(because the experiments were done in concentrated $\mathrm{NaClO}_{4}$ solutions only, it is currently not possible to definitively assign the value to one of these parameters) to closely fit the data, especially in relatively concentrated solutions. This value for $\mathrm{Np}(\mathrm{OH})_{3} \mathrm{ISA}^{0}-\mathrm{ClO}_{4}^{-}$is in the range of reported values for interactions of other neutral species with monovalent ions. ${ }^{(25)}$

The normalized aqueous $\mathrm{Np}(\mathrm{IV})$ concentrations from solvent extraction experiments in $\mathrm{NaClO}_{4}$ concentrations ranging from 0.103 to $6.54 \mathrm{~m}$ show close agreement with the concentrations predicted using the thermodynamic data (Tables I and II) described above (Fig. 8), indicating that the model developed in this study is consistent with the solvent extraction data. Xia et al., ${ }^{(21)}$ in interpreting their solvent extraction data for $\mathrm{Np}(\mathrm{IV})$-sulfate in $\mathrm{NaClO}_{4}$ concentrations ranging from 0.103 to $6.54 \mathrm{~m}$, assumed that the $\beta^{(0)}$ and $\beta^{(1)}$ for $\mathrm{Np}^{4+}-\mathrm{ClO}_{4}^{-}$and for $\mathrm{NpOH}^{3+}-\mathrm{ClO}_{4}^{-}$are identical to those for the corresponding $\mathrm{U}(\mathrm{IV})$ system. It is of interest to know whether the new parameters for $\mathrm{Np}^{4+}-\mathrm{ClO}_{4}^{-}$and $\mathrm{NpOH}^{3+}-$ $\mathrm{ClO}_{4}^{-}$impact the predictions made in Xia et al.. ${ }^{(21)}$ Therefore, modeling runs with the Xia et al. ${ }^{(21)}$ data were performed and results indicated that the inclusion of these parameters did not significantly impact the predictions made in Xia et al. ${ }^{(21)}$ This, we believe, is because the concentrations of both the $\mathrm{Np}^{4+}$ and $\mathrm{NpOH}^{3+}$ are very low as compared with the total soluble $\mathrm{Np}$ in the $\mathrm{Np}(\mathrm{IV})$-sulfate system investigated by Xia et al. ${ }^{(21)}$

\section{CONCLUSIONS}

The results presented in this paper show that significant complexation of $\mathrm{Np}(\mathrm{IV})$ by ISA ${ }^{-}$can occur under acidic as well as basic conditions and that the overall effect in solubilizing $\mathrm{NpO}_{2}(\mathrm{am})$ is dependent on the $\mathrm{pH}$ and ISA ${ }^{-}$concentration. The data reported in this study in conjunction with the data reported by Rai et $a l^{(14,15)}$ provide a basis to develop a comprehensive model for predicting $\mathrm{NpO}_{2}(\mathrm{am})$ solubility behavior in a wide range of $\mathrm{ISA}^{-}$concentrations 


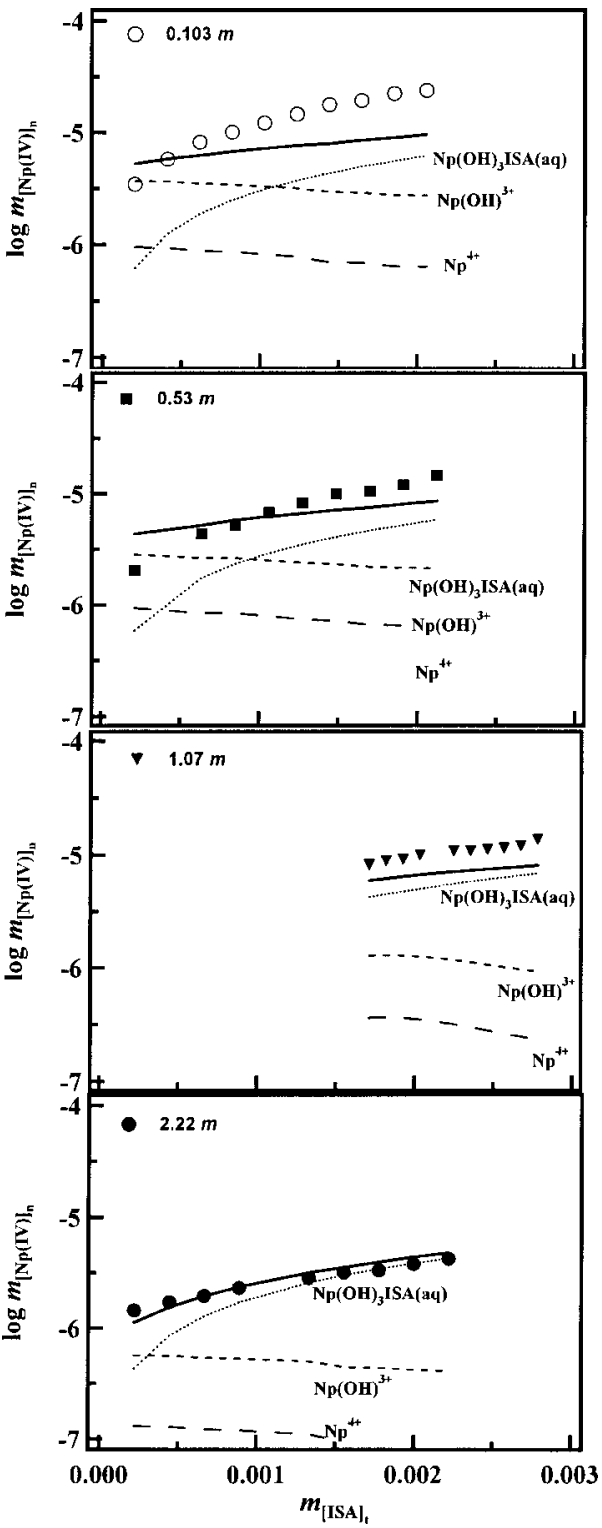

Fig. 8. Normalized aqueous $\mathrm{Np}(\mathrm{IV})$ concentrations $\left([\mathrm{Np}(\mathrm{IV})]_{\mathrm{n}}\right)$ as a function of total ISA concentrations. Solid line represents total concentrations, while other lines represent concentrations of different species, as identified, predicted using modeling parameters reported in Tables I and II. 


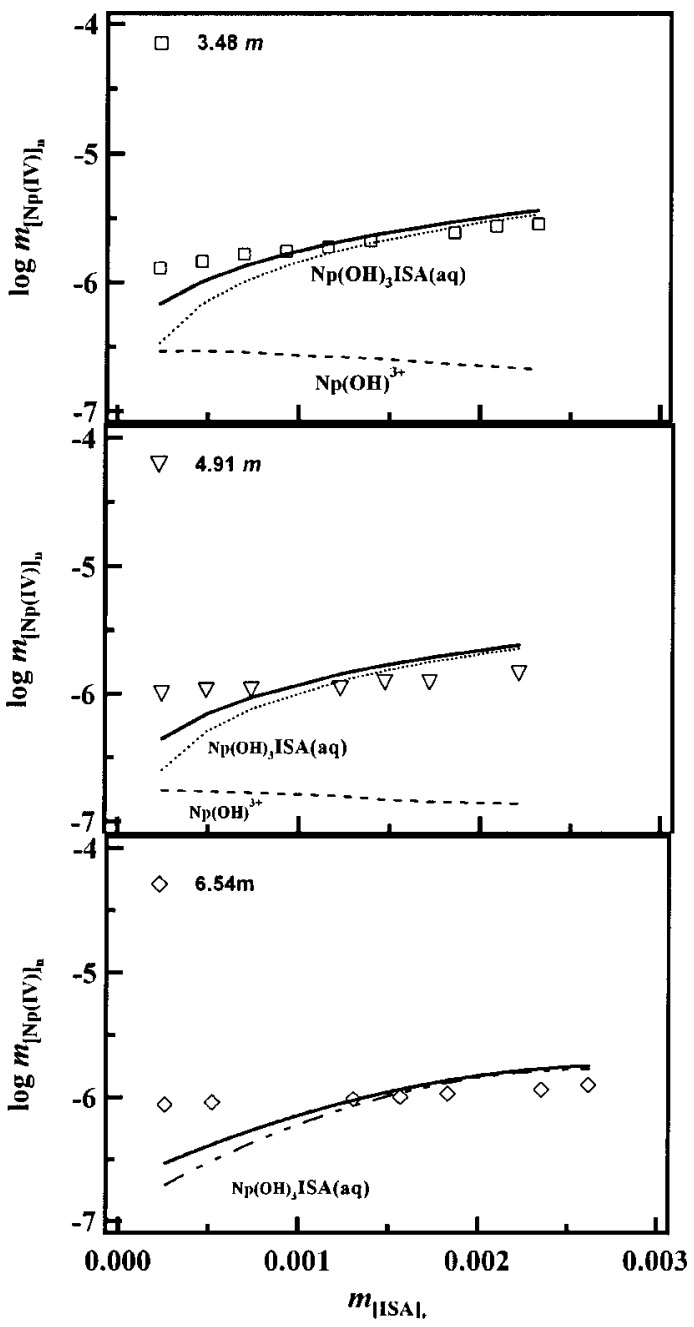

Fig. 8. Continued.

(0.0001-0.1 M), very acidic to highly alkaline conditions ( $\mathrm{pH} \sim 2-14$ ), and in dilute to concentrated $\mathrm{NaClO}_{4}(0.1-6.5 \mathrm{~m})$ solutions in the acidic region. The Pitzer ion-interaction parameters and the equilibrium constants developed/used in this study for the $\mathrm{Np}(\mathrm{IV})-\mathrm{H}^{+}-\mathrm{Na}^{+}-\mathrm{Ca}^{2+}-\mathrm{HISA}(\mathrm{aq})-\mathrm{ISA}^{-}-\mathrm{ISL}(\mathrm{aq})-\mathrm{OH}^{-}-\mathrm{H}_{2} \mathrm{O}$ and the $\mathrm{Ca}^{2+}-\mathrm{H}^{+}-\mathrm{HISA}(\mathrm{aq})-\mathrm{ISA}^{-}-\mathrm{ISL}(\mathrm{aq})-\mathrm{OH}^{-}-\mathrm{H}_{2} \mathrm{O}$ systems are summarized in Tables I and II. 


\section{ACKNOWLEDGMENTS}

This research was conducted at the Pacific Northwest National Laboratory [operated by Battelle for the U.S. Department of Energy (DOE) under contract DEAC06-76RL01830]. The research was carried out for the project (82715) on Development of Biodegradable Isosaccharinate-Containing Foams for Decontamination of Actinides funded by the DOE under the Environmental Management Sciences Program. Partial support for this research was provided by the Mitsubishi Materials Corporation (MMC), Tokyo, Japan. We thank Mr. Todd Gervais and Dean A. Moore for analytical help, Ryan Moore for drafting figures, and Ms. Debra M. Hinton for text processing of this document (NpISA 200330 revised JSC.doc).

\section{APPENDIX}

Table A.I. $\quad \mathrm{Ca}(\mathrm{ISA})_{2}$ (c) Solubility in NaISA Solutions of $\mathrm{pH}$ Values $~ 8.2$, Equilibrated for 48 Days

\begin{tabular}{ccc}
\hline \multicolumn{3}{c}{$\log m_{\mathrm{NaISA}}$} \\
\cline { 1 - 2 } Initially added & At equilibrium & $\log m_{\mathrm{Ca}}$ \\
\hline-1.940 & -1.63 & -2.239 \\
-1.636 & -1.49 & -2.444 \\
-1.464 & -1.46 & -2.568 \\
-1.347 & -1.35 & -2.702 \\
-1.170 & -1.17 & -2.829 \\
-0.959 & -0.96 & -2.991 \\
-0.724 & -0.70 & -3.336 \\
\hline
\end{tabular}

Table A.II. $\quad \mathrm{NpO}_{2}(\mathrm{am})$ Solubility in $0.0016 \mathrm{M}$ NaISA Containing $0.01 M \mathrm{Na}_{2} \mathrm{~S}_{2} \mathrm{O}_{4}$ and as a Function of $\mathrm{pH}$ and Equilibration Period

\begin{tabular}{|c|c|c|c|c|c|}
\hline \multicolumn{3}{|c|}{ 5-6 Days } & \multicolumn{3}{|c|}{13 Days } \\
\hline $\mathrm{pH}$ & $\log m_{\mathrm{Np}}$ & $\% \mathrm{~Np}(\mathrm{IV})$ & $\mathrm{pH}$ & $\log m_{\mathrm{Np}}$ & $\% \mathrm{~Np}(\mathrm{IV})$ \\
\hline 5.04 & -5.534 & 89 & 5.09 & -5.433 & 96 \\
\hline 5.56 & -6.292 & 54 & 5.55 & -5.975 & 94 \\
\hline 6.03 & -6.070 & 24 & 6.02 & -6.341 & 91 \\
\hline 6.51 & -6.437 & 20 & 6.54 & -6.239 & 93 \\
\hline 7.03 & -7.214 & 58 & 7.01 & -6.775 & 83 \\
\hline 7.49 & -6.561 & 29 & 7.48 & -6.752 & 25 \\
\hline
\end{tabular}


Table A.II. Continued

\begin{tabular}{ccccccc}
\hline & \multicolumn{2}{l}{$5-6$ Days } & & & \multicolumn{3}{c}{13 Days } \\
\cline { 1 - 2 } \cline { 5 - 6 } $\mathrm{pH}$ & $\log m_{\mathrm{Np}}$ & \% Np(IV) & $\mathrm{pH}$ & $\log m_{\mathrm{Np}}$ & $\%$ Np(IV) \\
\hline 7.99 & -6.744 & 37 & & 7.96 & -6.940 & 88 \\
8.47 & -6.880 & 54 & & 8.39 & -6.976 & 85 \\
8.81 & -7.155 & 62 & & 8.72 & -7.214 & 81 \\
9.24 & -7.247 & 55 & & 9.03 & -7.557 & 74 \\
9.64 & -7.319 & 66 & & 9.36 & -7.342 & 73 \\
10.18 & -7.307 & 69 & & 9.94 & -7.206 & 78 \\
10.78 & -7.371 & 68 & & 10.6 & -7.243 & 77 \\
11.87 & -7.433 & 60 & & 11.8 & -7.284 & 76 \\
$12.98^{a}$ & -7.256 & 71 & & $12.98^{a}$ & -7.360 & 72 \\
$13.82^{b}$ & -7.262 & 69 & $13.82^{b}$ & -7.262 & 71 \\
\hline
\end{tabular}

${ }^{a} \mathrm{pH}$ calculated by NONLIN from $0.125 \mathrm{~m} \mathrm{NaOH}$ initially added to the solutions.

${ }^{b} \mathrm{pH}$ calculated by NONLIN from $1.00 \mathrm{~m} \mathrm{NaOH}$ initially added to the solutions.

Table A.III. $\mathrm{NpO}_{2}(\mathrm{am})$ Solubility at $\mathrm{pH}$ Values of $\sim 12$ in $0.01 M \mathrm{Na}_{2} \mathrm{~S}_{2} \mathrm{O}_{4}$ and as a Function of NaISA Concentrations

\begin{tabular}{|c|c|c|c|c|c|c|}
\hline \multirow[b]{2}{*}{$\log m_{\text {ISA }}$} & \multicolumn{2}{|c|}{4 days } & \multicolumn{2}{|c|}{12 days } & \multicolumn{2}{|c|}{20 days } \\
\hline & $\log m_{\mathrm{Np}}$ & $\% \mathrm{~Np}(\mathrm{IV})^{\mathrm{a}}$ & $\log m_{\mathrm{Np}}$ & $\% \mathrm{~Np}(\mathrm{IV})$ & $\log m_{\mathrm{Np}}$ & $\% \mathrm{~Np}(\mathrm{IV})$ \\
\hline-3.699 & -8.490 & NL & -8.208 & 60 & -8.092 & 46 \\
\hline-3.398 & -8.227 & 73 & -8.247 & 79 & -7.845 & 68 \\
\hline-3.097 & -8.051 & 77 & -7.946 & 78 & -7.706 & 73 \\
\hline-2.796 & -7.666 & 89 & -7.651 & 89 & -7.305 & 83 \\
\hline-2.495 & -7.365 & 87 & -7.408 & 88 & -7.028 & 92 \\
\hline-2.201 & -7.137 & 94 & -6.991 & 91 & -6.058 & 95 \\
\hline-1.900 & -6.604 & 92 & -6.442 & 93 & -8.155 & 97 \\
\hline-1.600 & -5.929 & 91 & -5.908 & 91 & -5.516 & 98 \\
\hline-1.301 & -5.077 & 98 & -4.977 & 96 & -4.571 & 98 \\
\hline-1.000 & -4.758 & 95 & -4.641 & 97 & -4.294 & 96 \\
\hline
\end{tabular}

${ }^{a} \mathrm{NL}$ represents a sample for which a value is not available.

Table A.IV. Solvent Extraction Data ${ }^{a}$ for Np(IV) from ISA Solutions in Different Concentrations of $\mathrm{NaClO}_{4}$

\begin{tabular}{lccccc}
\hline$-\log m_{\mathrm{H}}^{+}$ & $\log m_{[\mathrm{ISA}] \mathrm{t}}^{\mathrm{b}}$ & $\log m_{[\mathrm{Np}(\mathrm{IV})] \mathrm{O}}^{\mathrm{b}}$ & $\log m_{[\mathrm{Np}(\mathrm{IV})] \mathrm{aq}}^{\mathrm{b}}$ & $\mathrm{D}$ & $\log m_{[\mathrm{Np}(\mathrm{IV})] \mathrm{n}}^{\mathrm{b}}$ \\
\hline \multicolumn{7}{c}{0.103} & $m \mathrm{NaClO}_{4}$ \\
1.890 & 0.000 & -4.887 & -4.723 & 0.685 & -5.836 \\
1.897 & -3.686 & -5.134 & -4.596 & 0.290 & -5.462 \\
1.899 & -3.385 & -5.301 & -4.538 & 0.173 & -5.238 \\
1.905 & -3.209 & -5.432 & -4.516 & 0.121 & -5.084 \\
1.908 & -3.084 & -5.531 & -4.524 & 0.098 & -4.993 \\
1.914 & -2.987 & -5.638 & -4.545 & 0.081 & -4.908 \\
1.919 & -2.908 & -5.687 & -4.517 & 0.068 & -4.830 \\
\hline
\end{tabular}


Table A.IV. Continued

\begin{tabular}{|c|c|c|c|c|c|}
\hline$-\log m_{\mathrm{H}}^{+}$ & $\log m_{[\mathrm{ISA}] \mathrm{t}}^{\mathrm{b}}$ & $\log m_{[\mathrm{Np}(\mathrm{IV})] \mathrm{O}}^{\mathrm{b}}$ & $\log m_{[\mathrm{Np}(\mathrm{IV})] \mathrm{aq}}^{\mathrm{b}}$ & $\mathrm{D}$ & $\log m_{[\mathrm{Np}(\mathrm{IV})] \mathrm{n}}^{\mathrm{b}}$ \\
\hline 1.930 & -2.841 & -5.779 & -4.525 & 0.056 & -4.746 \\
\hline 1.932 & -2.783 & -5.811 & -4.519 & 0.051 & -4.708 \\
\hline 1.940 & -2.732 & -5.875 & -4.521 & 0.044 & -4.647 \\
\hline 1.941 & -2.686 & -5.916 & -4.534 & 0.041 & -4.618 \\
\hline \multicolumn{6}{|c|}{$0.53 m \mathrm{NaClO}_{4}$} \\
\hline 1.840 & 0.000 & -4.772 & -4.726 & 0.901 & -5.955 \\
\hline 1.839 & -3.674 & -4.946 & -4.638 & 0.492 & -5.692 \\
\hline 1.849 & -3.197 & -5.208 & -4.563 & 0.227 & -5.355 \\
\hline 1.849 & -3.072 & -5.264 & -4.549 & 0.192 & -5.284 \\
\hline 1.856 & -2.975 & -5.358 & -4.523 & 0.146 & -5.165 \\
\hline 1.863 & -2.896 & -5.417 & -4.499 & 0.121 & -5.082 \\
\hline 1.867 & -2.829 & -5.512 & -4.513 & 0.100 & -5.001 \\
\hline 1.875 & -2.771 & -5.532 & -4.508 & 0.095 & -4.976 \\
\hline 1.877 & -2.719 & -5.588 & -4.505 & 0.083 & -4.918 \\
\hline 1.880 & -2.674 & -5.647 & -4.478 & 0.068 & -4.831 \\
\hline \multicolumn{6}{|c|}{$1.07 \mathrm{~m} \mathrm{NaClO}_{4}$} \\
\hline 1.840 & 0.000 & -5.004 & -4.721 & 0.520 & -5.716 \\
\hline 1.839 & -2.766 & -5.496 & -4.583 & 0.122 & -5.087 \\
\hline 1.840 & -2.740 & -5.530 & -4.582 & 0.113 & -5.052 \\
\hline 1.840 & -2.715 & -5.542 & -4.582 & 0.110 & -5.040 \\
\hline 1.847 & -2.692 & -5.581 & -4.586 & 0.101 & -5.004 \\
\hline 1.851 & -2.648 & -5.616 & -4.581 & 0.092 & -4.965 \\
\hline 1.857 & -2.628 & -5.604 & -4.570 & 0.093 & -4.966 \\
\hline 1.868 & -2.609 & -5.619 & -4.574 & 0.090 & -4.954 \\
\hline 1.879 & -2.590 & -5.634 & -4.574 & 0.087 & -4.940 \\
\hline 1.881 & -2.573 & -5.650 & -4.572 & 0.083 & -4.922 \\
\hline 1.886 & -2.556 & -5.701 & -4.569 & 0.074 & -4.867 \\
\hline \multicolumn{6}{|c|}{$2.22 m \mathrm{NaClO}_{4}$} \\
\hline 1.7917 & 0.000 & -4.761 & -4.710 & 0.890 & -5.949 \\
\hline 1.7847 & -3.654 & -4.805 & -4.643 & 0.689 & -5.838 \\
\hline 1.7867 & -3.353 & -4.856 & -4.618 & 0.578 & -5.762 \\
\hline 1.7927 & -3.177 & -4.914 & -4.619 & 0.508 & -5.706 \\
\hline 1.7947 & -3.052 & -4.930 & -4.564 & 0.431 & -5.634 \\
\hline 1.8037 & -2.875 & -5.000 & -4.547 & 0.352 & -5.546 \\
\hline 1.8197 & -2.809 & -5.050 & -4.548 & 0.315 & -5.498 \\
\hline 1.8237 & -2.751 & -5.087 & -4.561 & 0.298 & -5.474 \\
\hline 1.8287 & -2.699 & -5.129 & -4.549 & 0.263 & -5.420 \\
\hline 1.8327 & -2.654 & -5.155 & -4.526 & 0.235 & -5.371 \\
\hline \multicolumn{6}{|c|}{$3.48 m \mathrm{NaClO}_{4}$} \\
\hline 1.7275 & 0.000 & -4.697 & -4.661 & 0.919 & -5.963 \\
\hline 1.7275 & -3.635 & -4.736 & -4.622 & 0.769 & -5.886 \\
\hline 1.7275 & -3.333 & -4.761 & -4.595 & 0.684 & -5.835 \\
\hline 1.7305 & -3.157 & -4.785 & -4.562 & 0.599 & -5.777 \\
\hline 1.7365 & -3.032 & -4.811 & -4.568 & 0.572 & -5.757 \\
\hline 1.7415 & -2.936 & -4.845 & -4.565 & 0.526 & -5.721 \\
\hline
\end{tabular}


Table A.IV. Continued

\begin{tabular}{|c|c|c|c|c|c|}
\hline$-\log m_{\mathrm{H}}^{+}$ & $\log m_{[\mathrm{ISA}] \mathrm{t}}^{\mathrm{b}}$ & $\log m_{[\mathrm{Np}(\mathrm{IV})] \mathrm{O}}^{\mathrm{b}}$ & $\log m_{[\mathrm{Np}(\mathrm{IV})] \mathrm{aq}}^{\mathrm{b}}$ & $\mathrm{D}$ & $\log m_{[\mathrm{Np}(\mathrm{IV})] \mathrm{n}}^{\mathrm{b}}$ \\
\hline 1.7455 & -2.856 & -4.872 & -4.547 & 0.474 & -5.676 \\
\hline 1.7615 & -2.731 & -4.914 & -4.525 & 0.408 & -5.611 \\
\hline 1.7675 & -2.680 & -4.938 & -4.498 & 0.364 & -5.561 \\
\hline 1.7755 & -2.635 & -4.978 & -4.522 & 0.350 & -5.544 \\
\hline \multicolumn{6}{|c|}{$4.91 m \mathrm{NaClO}_{4}$} \\
\hline 1.642 & 0.000 & -4.617 & -4.675 & 1.143 & -6.058 \\
\hline 1.642 & -3.609 & -4.642 & -4.644 & 1.003 & -6.001 \\
\hline 1.645 & -3.308 & -4.642 & -4.619 & 0.947 & -5.976 \\
\hline 1.650 & -3.132 & -4.656 & -4.623 & 0.928 & -5.968 \\
\hline 1.658 & -2.910 & -4.652 & -4.614 & 0.917 & -5.962 \\
\hline 1.667 & -2.831 & -4.696 & -4.610 & 0.820 & -5.914 \\
\hline 1.674 & -2.764 & -4.718 & -4.631 & 0.818 & -5.913 \\
\hline 1.678 & -2.655 & -4.751 & -4.594 & 0.698 & -5.844 \\
\hline \multicolumn{6}{|c|}{$6.54 m \mathrm{NaClO}_{4}$} \\
\hline 1.554 & 0.000 & -4.605 & -4.675 & 1.173 & -6.069 \\
\hline 1.553 & -3.582 & -4.611 & -4.669 & 1.143 & -6.058 \\
\hline 1.554 & -3.281 & -4.613 & -4.655 & 1.102 & -6.042 \\
\hline 1.571 & -2.883 & -4.626 & -4.641 & 1.035 & -6.015 \\
\hline 1.577 & -2.804 & -4.639 & -4.639 & 0.999 & -6.000 \\
\hline 1.585 & -2.737 & -4.676 & -4.647 & 0.935 & -5.971 \\
\hline 1.597 & -2.627 & -4.666 & -4.607 & 0.874 & -5.941 \\
\hline 1.605 & -2.582 & -4.687 & -4.588 & 0.798 & -5.902 \\
\hline
\end{tabular}

${ }^{a}$ Extraction with DBM in toluene using 1:1 volume ratio of aqueous to organic phases.

${ }^{b} m_{\mathrm{xi}}$ represents molality of the subscripted species $\mathrm{x}$ and the subscript $\mathrm{i}$ refers to total for $\mathrm{i}=\mathrm{t}$, organic phase for $\mathrm{i}=\mathrm{o}$, aqueous phase for $\mathrm{i}=\mathrm{aq}$, and normalized for $\mathrm{i}=\mathrm{n}$. The normalized $\mathrm{Np}(\mathrm{IV})$ aqueous molality $\left[m_{[\mathrm{Np}(\mathrm{IV})] \mathrm{n}]}\right]$ was calculated by assuming $[\mathrm{Np}(\mathrm{IV})]_{0}=1.0 \times 10^{-6}$ and then dividing this number by $D$, the distribution ratio $\left(m[\mathrm{~Np}(\mathrm{IV})]_{\mathrm{O}} / m[\mathrm{~Np}(\mathrm{IV})]_{\mathrm{aq}}\right)$.

\section{REFERENCES}

1. B. F. Greenfield, A. D. Moreton, M. W. Spindler, S. J. Williams, and D. R. Woodwark, Mat. Res. Soc. Symp. Proc. 257, 299 (1992).

2. B. F. Greenfield, M. H. Hurdus, N. J. Pilkington, M. W. Spindler, and S. J. Williams, Mat. Res. Soc. Symp. Proc. 333, 705 (1994).

3. B. F. Greenfield, C. M. Linklater, A. D. Moreton, M. W. Spindler, and S. J. Williams, in Actinide Processing: Methods and, Materials, B. Misra and W. A. Averill, eds. (Mineral, Metals, and Materials Society, 1994), pp. 289-303.

4. B. F. Greenfield, G. J. Holton, M. H. Hurdus, N. O’Kelley, N. J. Pilkington, A. Rosevear, M. W. Spindler, and S. J. Williams, Mat. Res. Soc. Symp. Proc. 353, 1151 (1995).

5. A. D. Moreton, Mat. Res. Soc. Symp. Proc. 294, 753 (1993).

6. M. A. Glaus, A. Laube, S. Stallone, and L. R. Van Loon, Mat. Res. Soc. Symp. Proc. 506, 977 (1998).

7. M. A. Glaus, L. R. Van Loon, S. Achatz, A. Chodura, and K. Fischer, Anal. Chim. Acta 398, 111 (1999).

8. E. Wieland, J. Tits, P. Spieler, and J. P. Dobler, Mat. Res. Soc. Symp. Proc. 506, 573 (1998). 
9. X. Bourbon and P. Toulhoat, Radiochim. Acta 74, 315 (1996).

10. L. R. Van Loon, M. A. Glaus, A. Laube, and S. Stallone, Radiochim. Acta 86, 83 (1999).

11. K. Vercammen, M. A. Glaus, and L. R. Van Loon, Radiochim. Acta 84, 221 (1999).

12. K. Vercammen, M. A. Glaus, and L. R. Van Loon, Radiochim. Acta 89, 393 (2001).

13. R. L. Whistler, M. L. Wolfrom, and J. N. BeMiller, Methods in Carbohydrate Chemistry (Academic Press, New York, 1963).

14. D. Rai, L. F. Rao, and Y. Xia, J. Solution Chem. 27, 1109 (1998).

15. D. Rai, L. F. Rao, and D. A. Moore, Radiochim. Acta 83, 9 (1998).

16. H. M. Cho, D. Rai, N. J. Hess, Y. Xia, and L. Rao, J. Solution Chem., 32, 691 (2003).

17. L. R. Van Loon, M. A. Glaus, and K. Vercammen, Acta Chem. Scand. 53, 235 (1999).

18. K. Vercammen, M. A. Glaus, and L. R. Van Loon, Acta Chem. Scand. 53, 241 (1999).

19. D. Rai and J. L. Ryan, Inorg. Chem. 24, 247 (1985).

20. J. A. Schramke, D. Rai, R. W. Fulton, and G. R. Choppin, J. Radioanal. Nucl. Chem. 130, 333 (1989).

21. Y. Xia, L. Rao, D. Rai, and A. R. Felmy, Radiochim. Acta 86, 33 (1999).

22. D. Rai, A. R. Felmy, S. P. Juracich, and L. Rao, Estimating the Hydrogen Ion Concentration in Concentrated $\mathrm{NaCl}$ and $\mathrm{Na}_{2} \mathrm{SO}_{4}$ Electrolytes, SAND94-1949 (Sandia National Laboratory, Alburquerque, New Mexico, 1995).

23. M. S. Caceci and G. R. Choppin, Radiochim. Acta 33, 101 (1983).

24. K. S. Pitzer, J. Phys. Chem. 77, 268 (1973).

25. K. S. Pitzer, Ion Interaction Approach: Theory and Data Correlation (CRC Press, Boca Raton, FL 1991), Chap. 3.

26. S. M. Sterner, A. R. Felmy, J. R. Rustad, and K. S. Pitzer, Thermodynamic Analysis of Aqueous Solutions Using INSIGHT, PNWD-SA-4436 (Pacific Northwest National Laboratory, Richland, Washington, 1997).

27. D. Rai, N. J. Hess, A. R. Felmy, D. A. Moore, and M. Yui, Radiochim. Acta 84, 159 (1999).

28. D. Rai, A. R. Felmy, S. M. Sterner, D. A. Moore, M. J. Mason, and C. F. Novak, Radiochim. Acta 79, 239 (1997).

29. D. Rai, N. J. Hess, A. R. Felmy, D. A. Moore, M. Yui, and P. Vitorge, Radiochim. Acta 86, 89 (1999).

30. A. R. Felmy, D. Rai, and M. J. Mason, Radiochim. Acta 55, 177 (1991).

31. A. R. Felmy, D. Rai, S. M. Sterner, M. J. Mason, N. J. Hess, and S. D. Conradson, J. Solution Chem. 26, 233 (1997).

32. C. E. Harvie, N. Moller, and J. H. Weare, Geochim. Cosmochim. Acta 48, 723 (1984).

33. D. Rai, L. Rao, H. T. Weger, A. R. Felmy, G. R. Choppin, and M. Yui, Thermodynamic Data for Predicting Concentration of Th(IV), U(IV), Np(IV) and Pu(IV) in Geologic Environments, JNC TH8400 99-009 (Japan Nuclear Cycle Development Institute, Tokai Works, Japan, 1999).

34. D. Rai, A. R. Felmy, and J. L. Ryan, Inorg. Chem. 29, 260 (1990). 